Woods Hole Oceanographic Institution

WHOI-99-14

Technical Report

September 1999

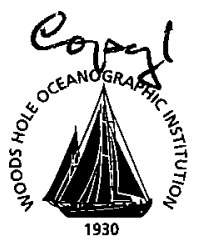

\title{
The Horizontal Mooring: A Two-Dimensional Array, Description of the Array, Components, Instrumentation, Deployment and Recovery Operations
}

\author{
by \\ Richard P. Trask \\ Steven P. Anderson \\ Bryan S. Way \\ William M. Ostrom \\ Walter Paul \\ Mark A. Grosenbaugh \\ Jason I. Gobat \\ Robert A. Weller
}

September 1999

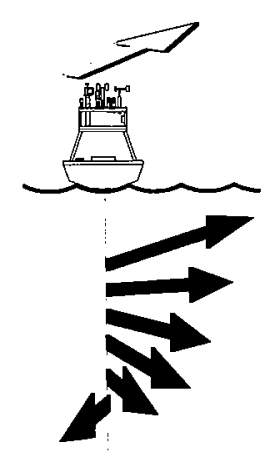


WHOI-99-14

UOP-99-02

The Horizontal Mooring: A Two-Dimensional Array, Description of the Array, Components, Instrumentation, Deployment and Recovery Operations

\author{
by \\ Richard P. Trask \\ Steven P. Anderson \\ Bryan S. Way \\ William M. Ostrom \\ Walter Paul \\ Mark A. Grosenbaugh \\ Jason I. Gobat \\ Robert A. Weller \\ Woods Hole Oceanographic Institution \\ Woods Hole, Massachusetts 02543
}

September 1999

\title{
Technical Report
}

Funding was provided by the Office of Naval Research under Grant No. N00014-97-1-0158.

Reproduction in whole or in part is permitted for any purpose of the United States Government. This report should be cited as Woods Hole Oceanog. Inst. Tech. Rept., WHOI-99-14.

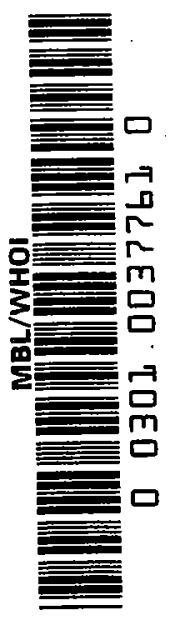

Approved for public release; distribution unlimited.

Approved for Distribution:

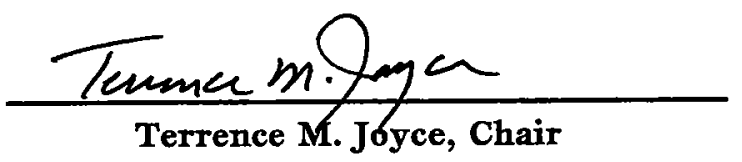

Department of Physical Oceanography 



\section{Abstract}

A moored two-dimensional array with instrumentation distributed both horizontally and vertically was deployed for 27 days in August 1998 at an 85 meter deep site in Massachusetts Bay near Stellwagon basin. The horizontal mooring consisted of a 160meter long horizontal element positioned at a depth of 20 meters between two subsurface moorings. Suspended below the horizontal member were five 25 -meter long vertical strings. The vertical strings had a horizontal separation of 30 meters and each had instruments at depths of $20,25,30,35,40$ and 45 meters. Instrumentation deployed on the two-dimensional array included acoustic current meters, temperature sensors, conductivity measuring instruments, pressure sensors and motion monitoring packages.

This report includes a detailed description of the two-dimensional array, the anchoring system and the instrumentation that were deployed. Also included is a description of the deployment and recovery techniques that were employed as well as an assessment of the performance of the array. 



\section{Table of Contents}

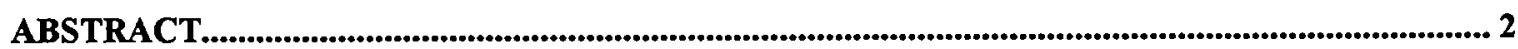

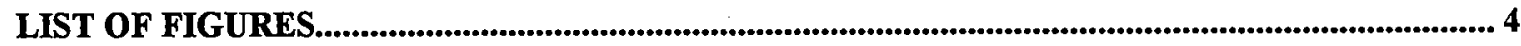

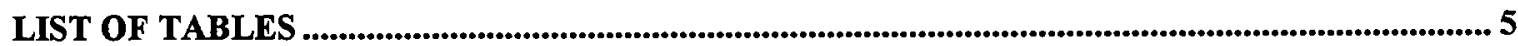

SECTION 1: INTRODUCTION......................................................................................................... 6

SECTION 2: DESCRIPTION OF THE ARRAY ........................................................................... 7

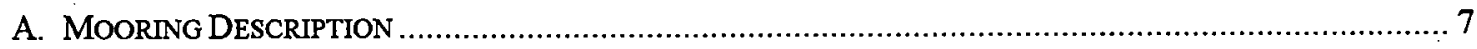

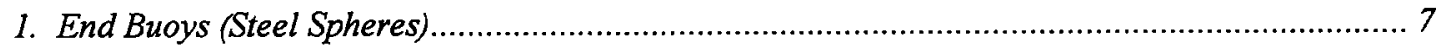

2. End Buoy Mooring Details........................................................................................ 11

3. Horizontal Mooring Member.............................................................................................. 12

4. Instrumentation Attachment to Horizontal Member ........................................................ 12

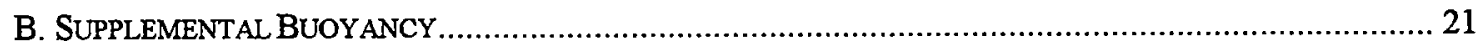

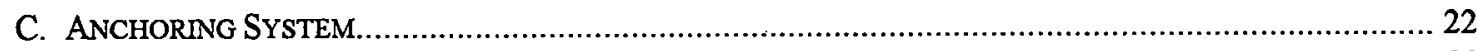

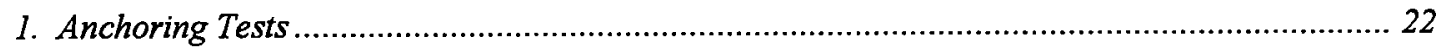

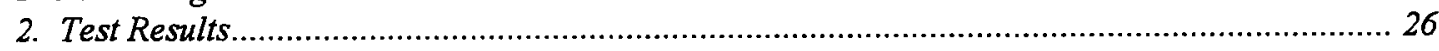

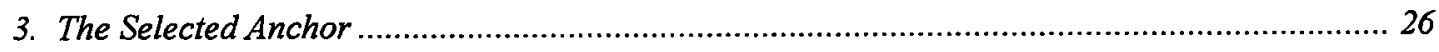

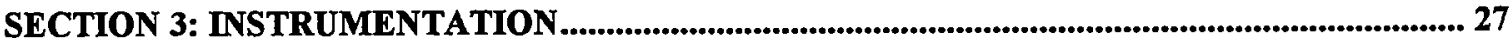

A. FSI 3D-ACM

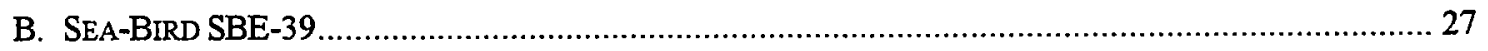

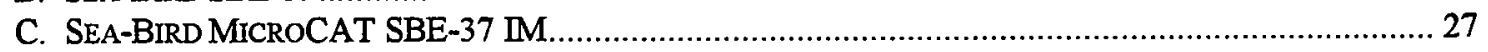

D. BRANCKER RESEARCH, LTD. XL-200

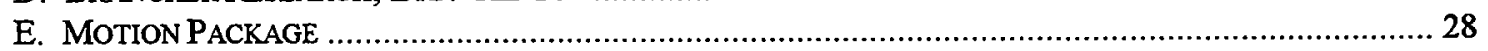

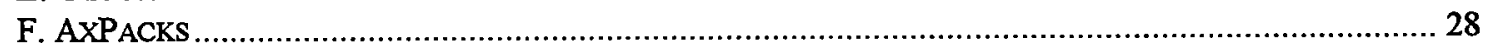

SECTION 4: DEPLOYMENT AND RECOVERY OPERATIONS.............................................. 29

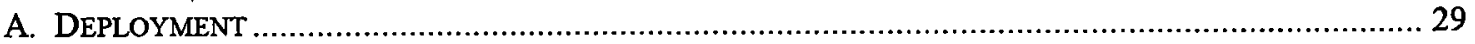

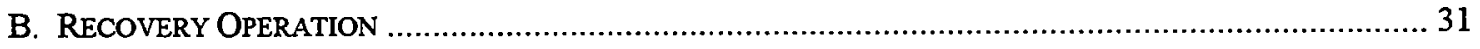

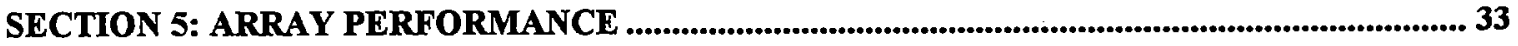

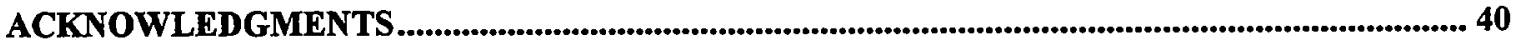

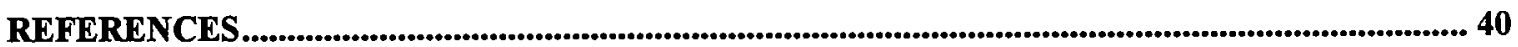

APPENDIX 1: INSTRUMENT LOCATIONS WITHIN THE HORIZONTAL ARRAY ................. 41

APPENDIX 2: TIME MARKS ON TEMPERATURE SENSING INSTRUMENTS.......................... 49

APPENDIX 3: PRESSURE TELEMETRY SYSTEM.....................................................................51 


\section{List of Figures}

Figure 1: (a) Side view of the horizontal mooring.........................................................

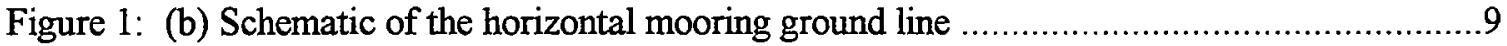

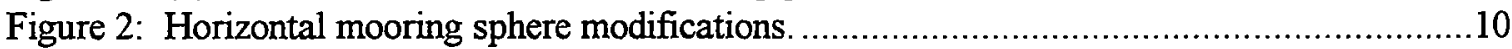

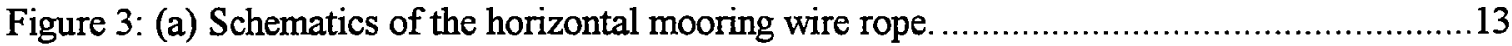

Figure 3: (b) Schematics of the horizontal mooring wire rope elements.................................14

Figure 4: Photograph of the modified cage used with the FSI 3D-ACM..............................15

Figure 5: Photograph of the clamp used to attach the vertical strings .....................................16

Figure 6: (a) Horizontal mooring wire clamp plates. .........................................................18

Figure 6: (b) Horizontal mooring wire clamp backing plates...........................................19

Figure 7: Photograph of the clamp attaching the temperature recorder to the vertical

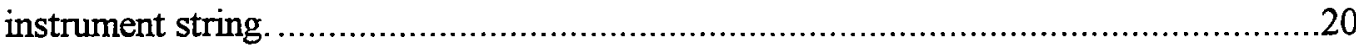

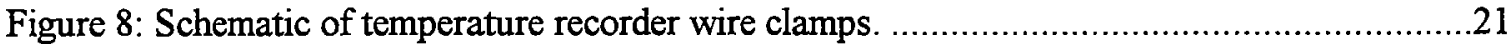

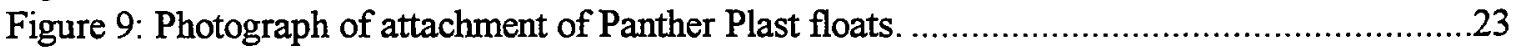

Figure 10: Clamp used to attach 17-inch glass balls to wire rope for supplemental buoyancy......23

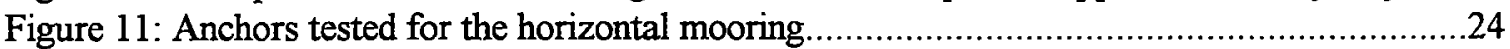

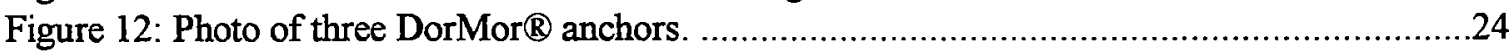

Figure 13: A schematic of the configuration of the anchor holding tests .................................24

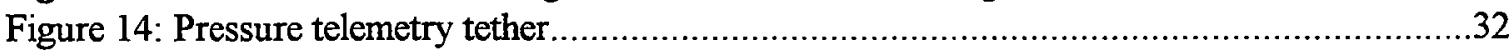

Figure 15: Anchor locations for instrumented platforms at mooring site. .................................34

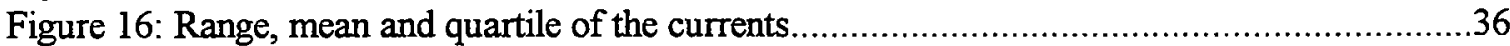

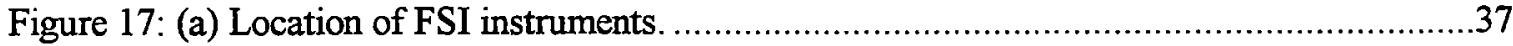

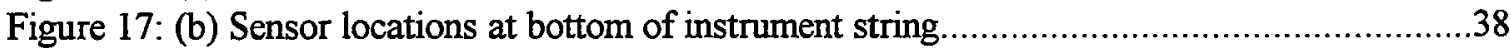

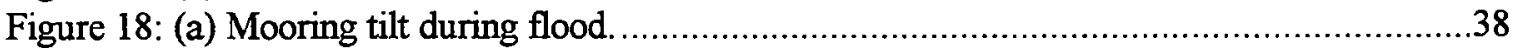

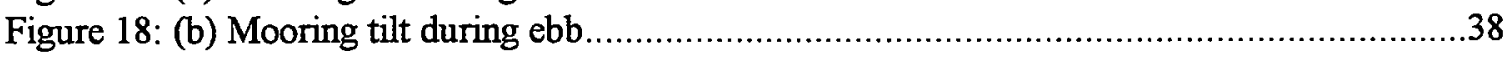

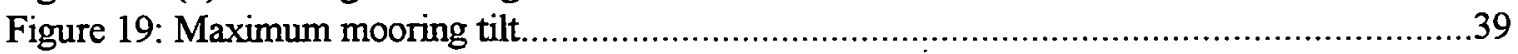

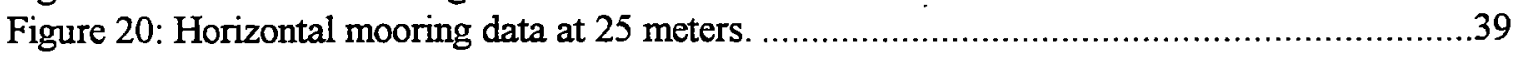

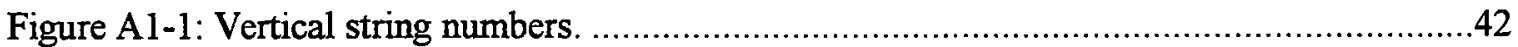

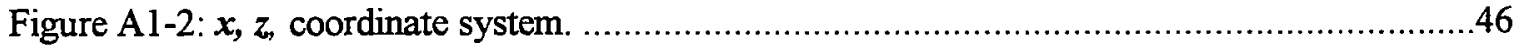

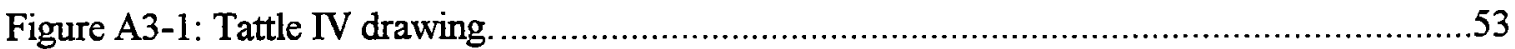

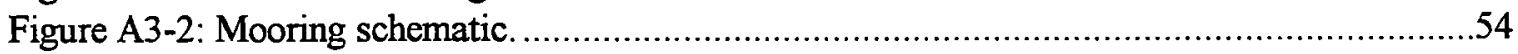




\section{List of Tables}

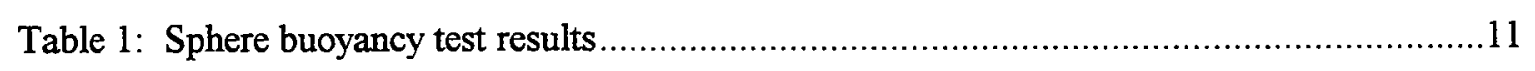

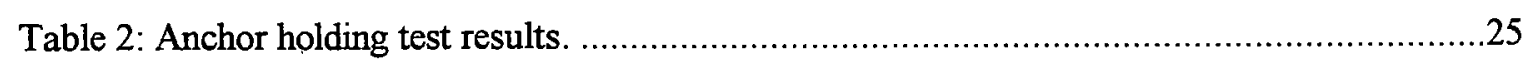

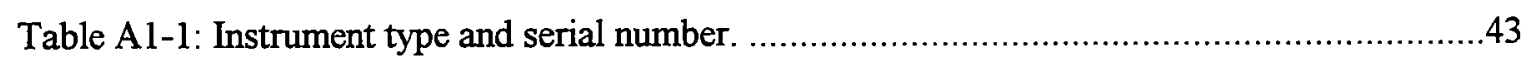

Table A1-2: Coordinates of deployed instrumentation using $x, z$ coordinate system..................47

Table A3-1: Program used to query MicroCAT ......................................................52 


\section{Section 1: Introduction}

In 1997 preliminary work began toward developing a three-dimensional moored array for studying the upper ocean from the very near surface down through the permanent thermocline in shallow and deep water. As a first step in its development, a two-dimensional array with the capability of making measurements in the vertical along one horizontal axis was designed and tested. The design of such an array poses the same engineering challenges as the more complex three-dimensional array, and is, therefore, a necessary first step. This report documents the work completed to date (mid-1999) on the two-dimensional moored array project, with emphasis on the 1998 effort.

A numerical model of a subsurface horizontal mooring was developed in 1997 to aid in the evaluation of horizontal mooring designs. The numerical simulation and study of the performance of the horizontal mooring were performed using a general purpose numerical code, developed at WHOI, for calculating statistics and dynamic response of moored and towed oceanographic systems (Gobat et al., 1997). The simulation is built around a mathematical model of cable dynamics that includes the effects of geometric nonlinearities, material nonlinearities, material bending stiffness, and material torsion. This permits accurate threedimensional modeling of systems in which the cable goes slack. The nonlinear, one-sided boundary condition at the seabed is modeled as an elastic foundation for systems with cable lying on the bottom. The numerical implementation includes an adaptive time-stepping algorithm to speed the solution of problems with high nonlinearity.

The simulation was used to model the behavior of the subsurface horizontal mooring under sea-state and current forcing up to the worst hurricane scenario. Line tensions, tension fluctuations, motion of the corner buoys and component accelerations were so established. The results allow the detail mooring design to be within acceptable safe working load levels of all components.

On 19 August 1997, the first horizontal array was deployed off Provincetown, Massachusetts, in 100 meters of water. An instrumented horizontal element, 100 meters long, was tensioned between two subsurface moorings at 20 meters depth. Three current meters and five temperature/pressure recorders were deployed along the horizontal element recording data every one and two minutes respectively. In addition to these instruments, a motion-measuring package was deployed in one of the two subsurface mooring spheres. Three surface buoy guard moorings were deployed around the array to protect it from any damage due to fishing activities. One of the three surface buoys was deployed with an internally recording wind speed and direction sensor to monitor the surface forcing. A significant storm passed through the area two days after deployment, testing the holding power of the anchors and the integrity of the system under rough weather conditions. The array was successfully recovered on 27 August 1997. All instrumentation deployed along the horizontal element collected data for the entire deployment.

Experience gained from the first deployment led to the design of a new, modified, twodimensional array, which had sensors distributed both horizontally and vertically. To evaluate the unique capability of this two-dimensional array, a joint engineering and scientific deployment was planned. The scientific focus was to explore the coherence at short horizontal and 
temporal scales of the internal waves on the continental shelf, specifically targeting the effect of internal solitons on sediment transport. Working in conjunction with the United States Geological Survey (USGS), a site was selected in Massachusetts Bay near Stellwagon basin in 85 meters of water.

A two-dimensional mooring was deployed on 6 August 1998 from the R/V Argo Maine. The horizontal mooring consisted of a 160 -meter long horizontal element positioned at a depth of 20 meters between two subsurface moorings. Suspended below the horizontal member were five, 25 -meter long vertical strings. The vertical strings had a horizontal separation of 30 meters and each had instruments at depth of $20,25,30,35,40$ and 45 meters. The central vertical string was instrumented with an acoustic current meter, five temperature- and conductivity-measuring instruments, and one acceleration-sensing package. The other four vertical strings were each instrumented with six temperature recorders. The instruments at the bottom of the vertical strings also measured pressure. Two additional acoustic current meters were deployed along the horizontal member. Pressure sensors and motion monitoring packages were deployed at the ends of the horizontal member. The two-dimensional array was successfully recovered on 1 September 1998 after 27 days on station.

This report will include a detailed description of the two-dimensional moored array, the instrumentation that was deployed, the technique used to deploy and recover the array, as well as an assessment of its performance.

\section{Section 2: Description of the Array}

\section{A. Mooring Description}

The two-dimensional array consisted of two subsurface moorings with a taut horizontal member stretched between them (Figure 1a). Figure 1b shows the details of the ground line that was deployed as a means of properly tensioning the array. A description of the subsurface moorings will be followed by a detailed description of the horizontal member with its associated vertical strings.

\section{End Buoys (Steel Spheres)}

Each of the two subsurface moorings had a 48-inch diameter steel sphere as their primary buoyancy. The spheres were modified with new bales to accommodate the two points of attachment required for the array (Figure 2). These same spheres had been used during the first horizontal mooring deployment in 1997. Analysis of the pressure data collected from that mooring revealed that there was a persistent slope along the array with one side approximately six meters deeper than the other. Both spheres were assumed to be identical, and the manufacturer's buoyancy specifications were used in the design process. The numerical model suggested that one way for the observed slope to persist throughout all the variable tidal current forcing was to have one of the subsurface spheres with $20 \%$ less buoyancy than the other. 


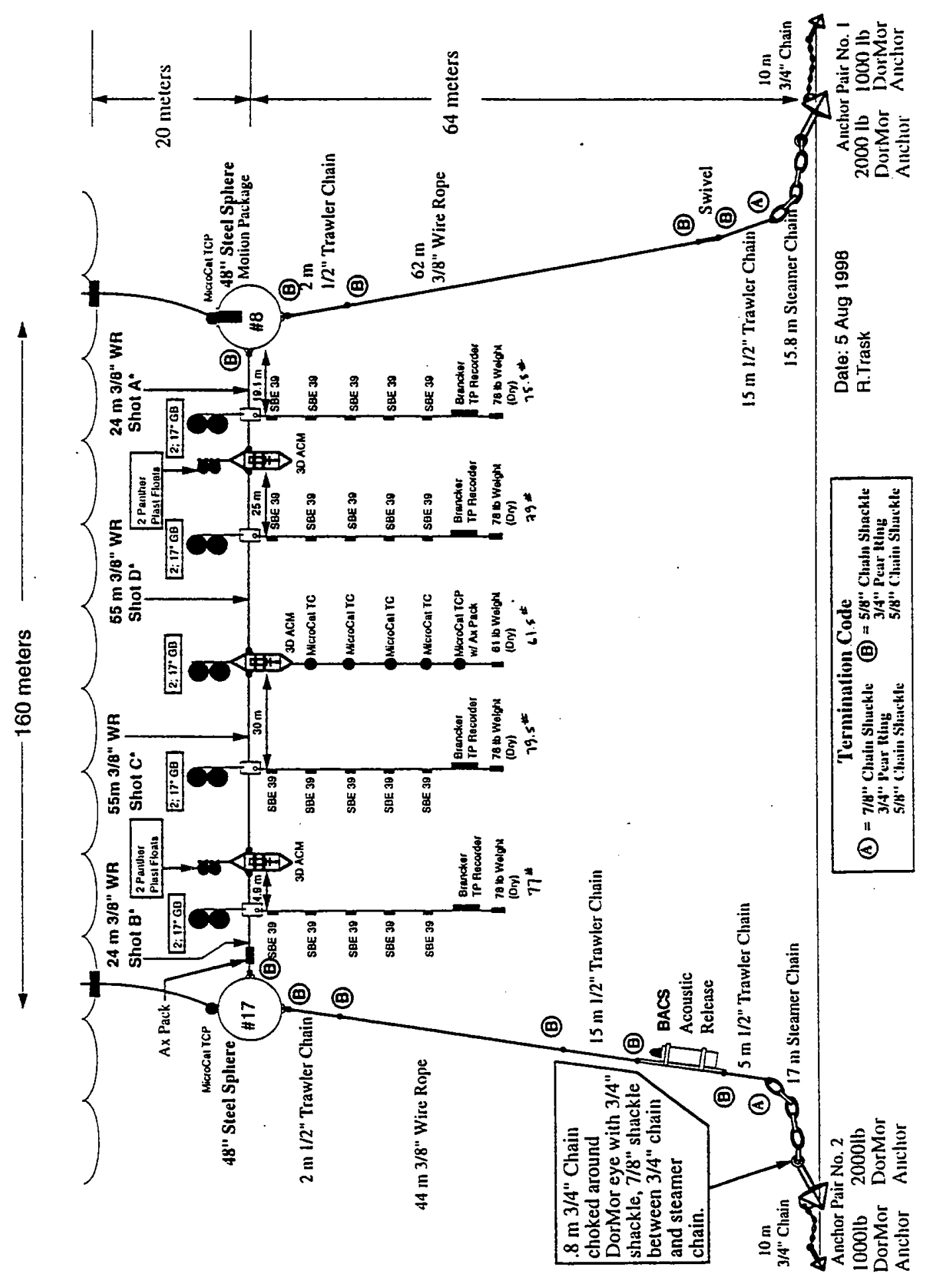

Figure 1: (a) Side view of the horizontal mooring. 


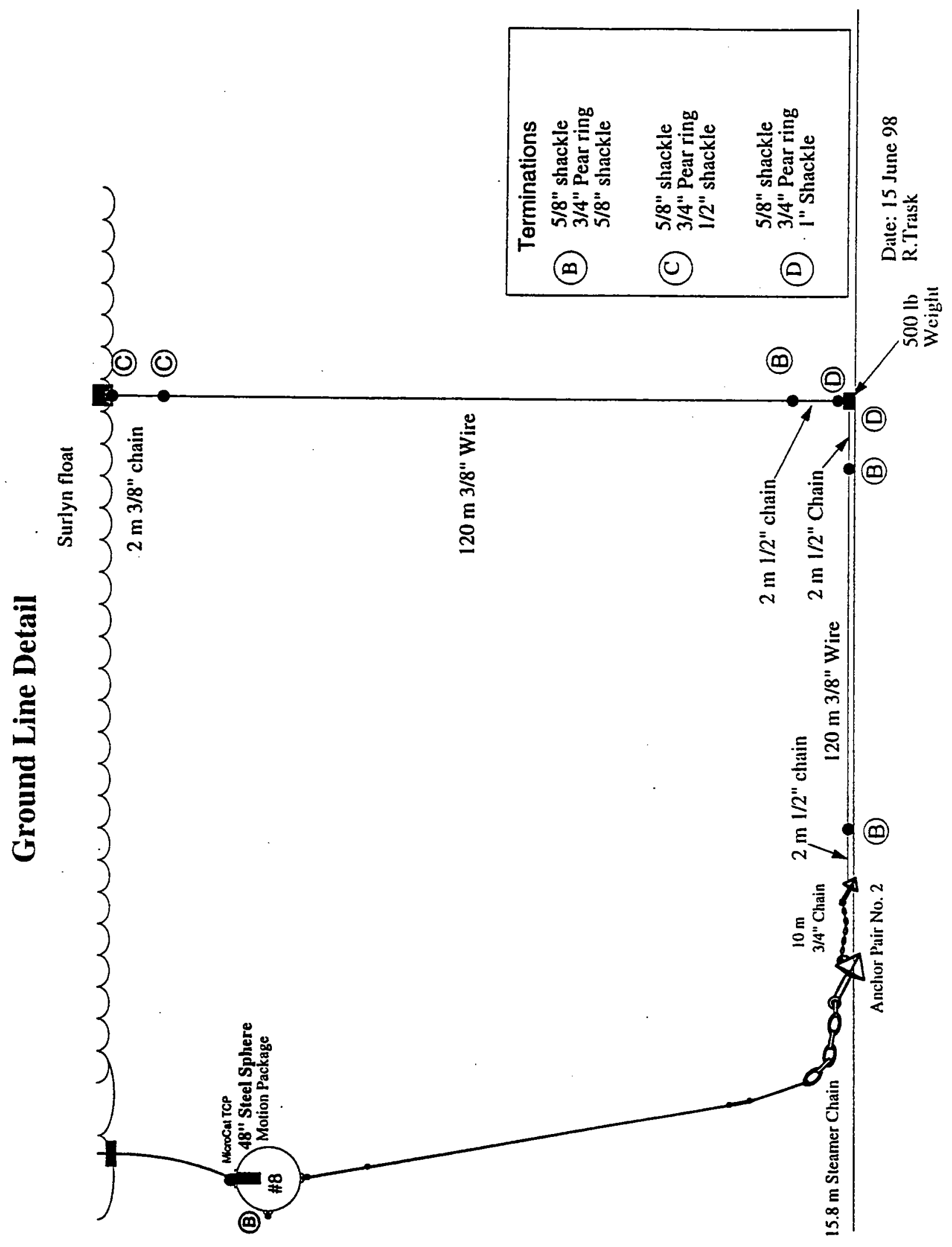

Figure 1: (b) Schematic of the horizontal mooring ground line deployed with the twodimensional array. 

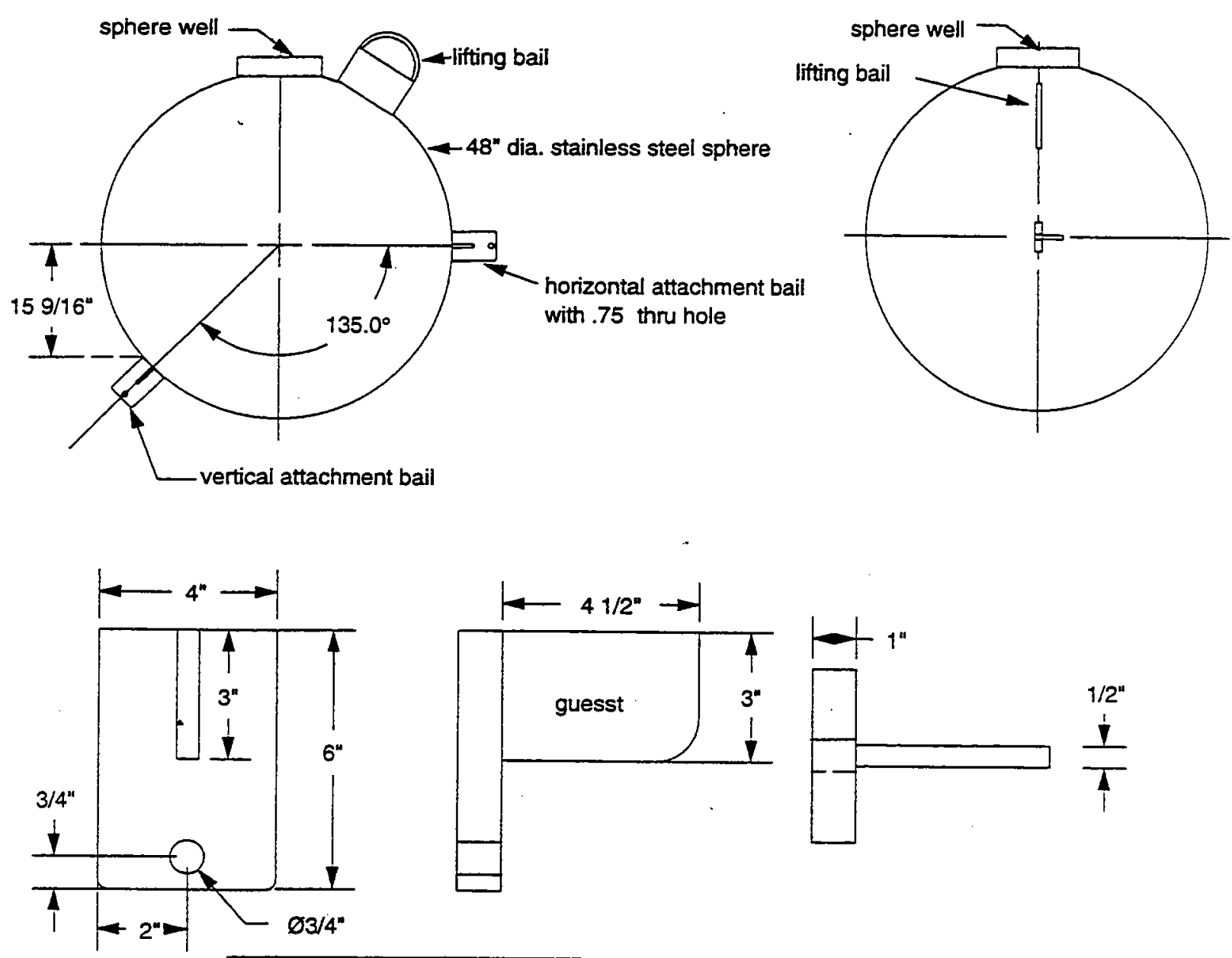

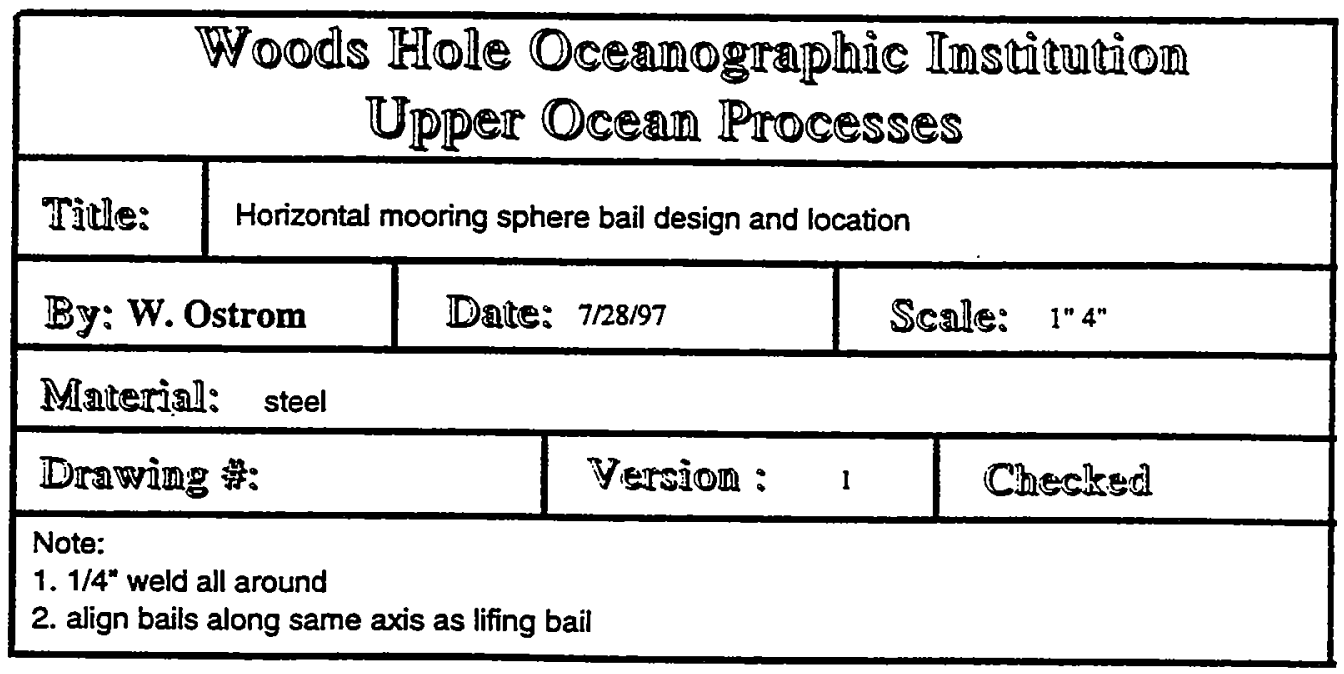

Figure 2: Horizontal mooring sphere modifications. 
The buoyancy of the two spheres was determined experimentally at the WHOI dock. An anchor of known weight in water was attached below each sphere, and the spheres were lowered into the water with a crane until the spheres were completely submerged. The weight in water of the sphere-anchor assembly was measured using a load cell. The results of the buoyancy tests appear in Table 1 .

Table 1: Sphere buoyancy test results

\begin{tabular}{|c|c|c|}
\hline \multicolumn{3}{|c|}{$\begin{array}{c}\text { Test date: } 17 \text { March } 1998 \\
\text { Anchor Wet Weight: } 2050 \text { pounds }\end{array}$} \\
\hline Sphere \# & $\begin{array}{l}\text { Weight in water } \\
\text { with anchor }\end{array}$ & Net buovancy \\
\hline 17 & 570 pounds & 1480 pounds \\
\hline 8 & 880 pounds & 1170 pounds \\
\hline
\end{tabular}

Although the spheres appeared identical, there was considerable difference in their available buoyancy. These buoyancy differences were taken into consideration in the design of the two-dimensional array deployed in 1998.

\section{End Buoy Mooring Details}

A two-meter shot of 1/2-inch trawler chain was attached directly below the sphere for ease in handling during deployment and recovery. Below the two-meter shot of chain was 3/8inch diameter $3 \times 19$ jacketed wire rope. The length of each wire rope was adapted to lead to a horizontal long-line positioning despite the differences in buoyancy of the two comer buoys.

One of the two subsurface moorings had an acoustic release as a means of back-up recovery. Above and below the acoustic release were two lengths of $1 / 2$-inch trawler chain. The longer length (15 meters) above the release was intended as an adjustable shot had there been a discrepancy between the design water depth and the actual depth. Since there was no acoustic release on the other subsurface mooring, a single 15 -meter length of $1 / 2$-inch trawler chain was deployed below the $3 / 8$-inch diameter wire rope with a 5 -ton swivel between the two.

Below the 1/2-inch chain on each mooring was a length of 1.25-inch steamer chain. The steamer chain weighed, on average, 46 pounds $(21 \mathrm{~kg})$ per meter. It was included in the design to reduce the angle between the bottom and the direction of the force exerted on the anchor. A pair of DorMor $\$$ inverted pyramid-shaped mooring anchors were used to secure each subsurface mooring leg. According to the manufacturer, the DorMor ${ }^{\circledR}$ style anchor has the greatest holding capacity when used in conjunction with large scope moorings. The steamer chain was used to replicate the low angle of pull characteristic of a large (3:1) scope mooring. The horizontal mooring anchor system consisted of a 2000-pound and a 1000-pound DorMor $®$ anchor connected by a 10 -meter length of $3 / 4$-inch chain. The primary anchor was the 
larger of the two. The smaller anchor was added due to uncertainties about the holding capacity of the DorMor $\mathbb{B}$ anchors in the expected bottom conditions and in this particular application. The DorMor ${ }^{\circledR}$ anchor was chosen after testing several anchor types. The results of those tests are described in Section $2 \mathrm{C}$.

The DorMorß anchors were modified with additional bales so that two anchors could be used in series as shown in Figure 1, as well as tensioned during the deployment operations as described in Section 4 of this report.

\section{Horizontal Mooring Member}

Stretched between the two 48-inch diameter spheres was a horizontal member consisting of four lengths of 3/8-inch diameter $3 \times 19$ jacketed wire rope. The details of the wire shots are shown in Figure 3(a) and (b). Instrumentation was either clamped to the horizontal wire or placed in line with the wire. Three Falmouth Scientific, Inc. (FSI), 3D acoustic current meters (3D-ACM) were deployed in line with the horizontal wire. The FSI 3D-ACM cages were modified with additional bales so that the current meter could be deployed in-line with the horizontal wire and still maintain the vertical orientation required for proper operation of the compass (Figure 4).

Every effort was made to reduce the loading along the horizontal member. Typical wire rope terminations consist of a closed swage socket and a strain relief boot. To connect instrumentation in-line, the normal complement of mooring hardware consists of a shackle-linkshackle combination. To reduce the localized loading, the horizontal mooring wire shots were terminated with an open swage socket. The open socket was placed over an instrument bale and connected by means of a single bolt. The open swage sockets used in this application were Crosby S-501 sockets for $7 / 16$-inch or $1 / 2$-inch diameter wire rope.

This configuration reduced the loading; however, because links were not used, there was no readily available place where the mooring could be stopped off either during deployment or recovery. A light-weight solution to this problem was the addition of Yale grips $($ to the wire at selected locations. The Yale grip $B$ works on the same principle as a Chinese finger. It has an eye with four long tails of Kevlar flat braid that are spirally wrapped around the wire. The Yale grip $®$ provides an eye at which the mooring can be stopped off. As tension is applied to the eye the spiraled Kevlar material tightens around the wire. The ends of the wire shots that were connected to the two 48 -inch diameter spheres had conventional closed swage sockets and strain relief boots. The common hardware complement of shackle-link-shackle was used.

\section{Instrumentation Attachment to Horizontal Member}

Instrumentation that was not placed in line with the horizontal member was clamped to the wire. Four of the five vertical strings shown in Figure 1 were clamped to the horizontal member by means of a pair of PVC plates. Figure 5 is a photograph of the upper part of a 
Closed swage socket $w /$ boot

Open swage socket w/boot

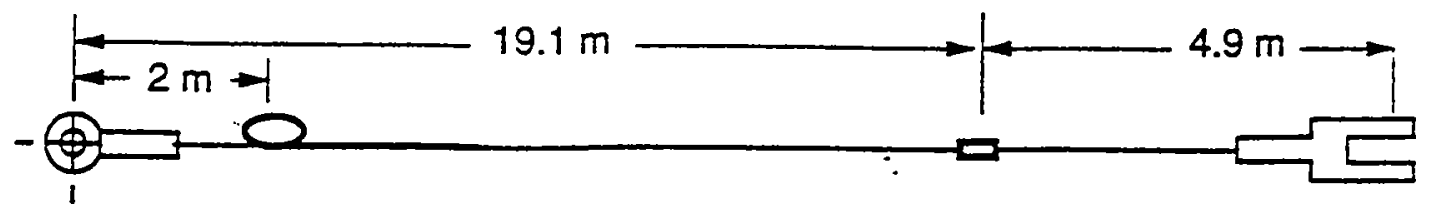

Shot A Quantity Required: 1

24 meter long shot of $3 / 8$ " diameter $3 \times 19$ TB Wire Rope

Marked 19.1 meters from the closed eye with Duct tape indicating "Temperature

String". End with closed eye should be labelled "Marked $19.1 \mathrm{~m}$ from this end".

Other end should be labelled "Marked $4.9 \mathrm{~m}$ from this end".

Yale Grip eye located 2 meters from closed swage socket, oriented as shown

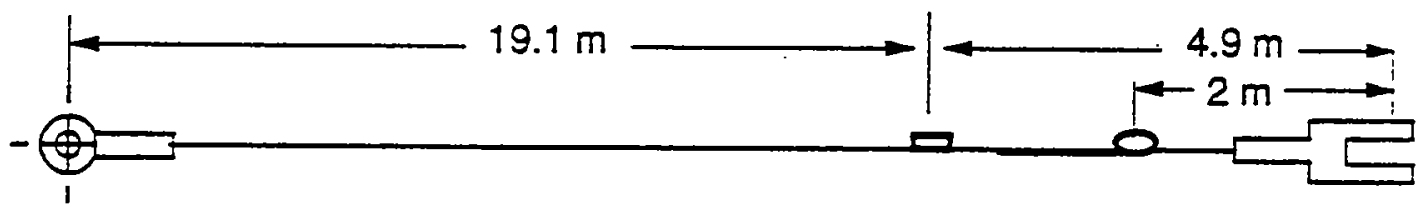

Shot $B \quad$ Quantity Required: 1

24 meter long shot of 3/8" diameter $3 \times 19$ TB Wire Rope

Marked 19.1 meters from the closed eye with Duct tape indicating "Temperature String". End with closed eye should be labelled "Marked $19.1 \mathrm{~m}$ from this end".

Other end should be labelled "Marked $4.9 \mathrm{~m}$ from this end".

Yale Grip eye located 2 meters from open swage socket, oriented as shown

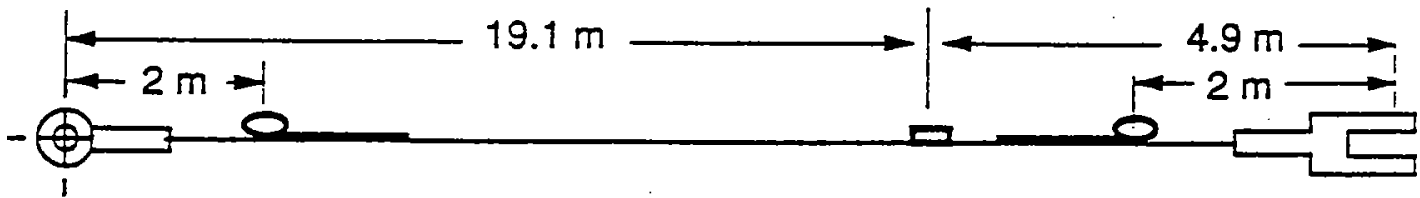

Spare Shot for A or B Quantity Required: 1

24 meter long shot of 3/8" diameter $3 \times 19$ TB Wire Rope

Marked 19.1 meters from the closed eye with Duct tape indicating "Temperature

String". End with closed eye should be labelled "Marked $19.1 \mathrm{~m}$ from this end".

Other end should be labelled "Marked $4.9 \mathrm{~m}$ from this end".

Two Yale Grips with eyes located 2 meters from each end, oriented as shown

Figure 3: (a) Schematics of the horizontal mooring wire rope. 


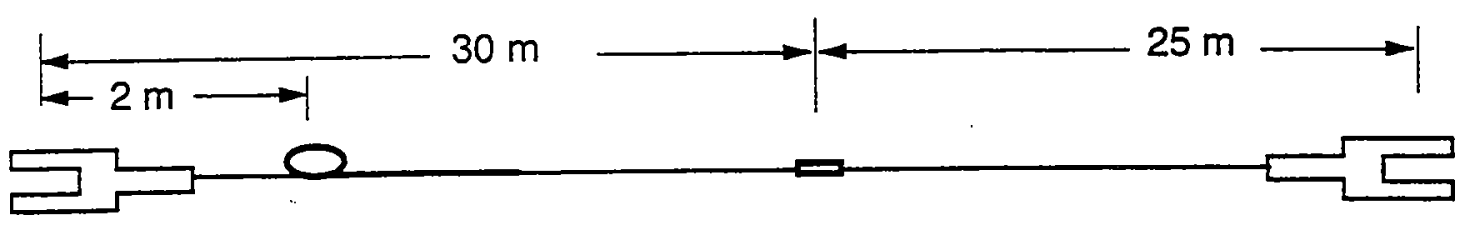

Shot C Quantity Required: 1

55 meter long shot of $3 / 8^{\prime \prime}$ diameter $3 \times 19$ TB Wire Rope

Marked 25 meters in from one end with Duct tape indicating

"Temperature String". End from which measurement is made should be labelled "Marked $25 \mathrm{~m}$ from this end".

Other end should be labelled "Marked $30 \mathrm{~m}$ from this end".

Yale grip eye located 2 meters in on $30 \mathrm{~m}$ segment oriented as shown.

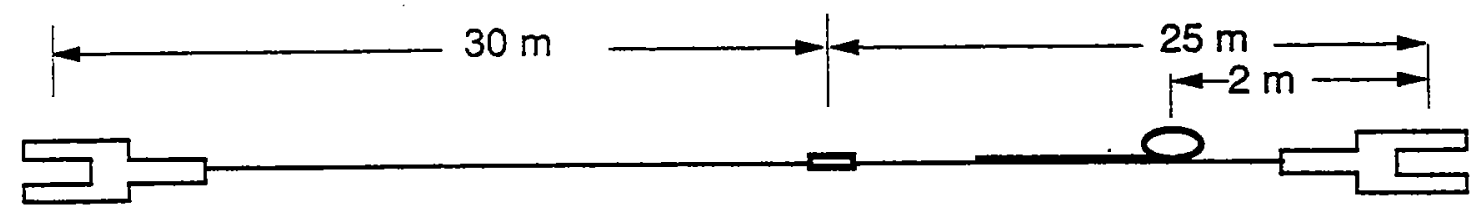

Shot D Quantity Required: 1

55 meter long shot of 3/8" diameter 3x19 TB Wire Rope

Marked 25 meters in from one end with Duct tape indicating

"Temperature String". End from which measurement is made should be labelled "Marked $25 \mathrm{~m}$ from this end".

Other end should be labelled "Marked $30 \mathrm{~m}$ from this end".

Yale grip eye located 2 meters in on $25 \mathrm{~m}$ segment oriented as shown.

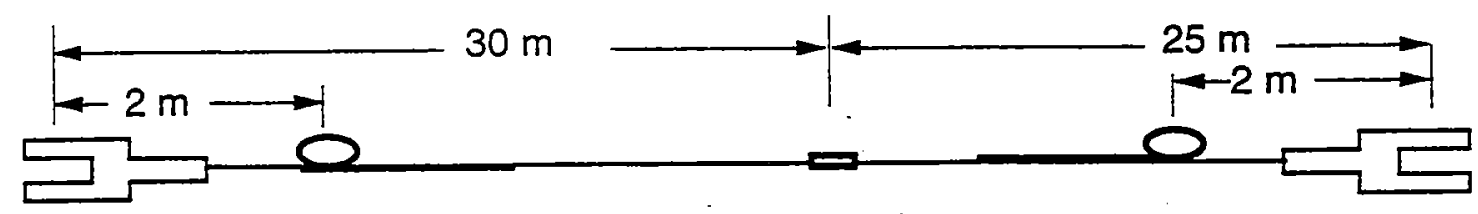

Spare for Shot $C$ or $D \quad$ Quantity Required: 1

55 meter long shot of $3 / 8$ " diameter $3 \times 19$ TB Wire Rope

Marked 25 meters in from one end with Duct tape indicating

"Temperature String". End from which measurement is made should be labelled "Marked $25 \mathrm{~m}$ from this end".

Other end should be labelled "Marked $30 \mathrm{~m}$ from this end".

Two Yale grip eyes located 2 meters from each end, oriented as shown.

Figure 3: (b) Schematics of the horizontal mooring wire rope elements. 


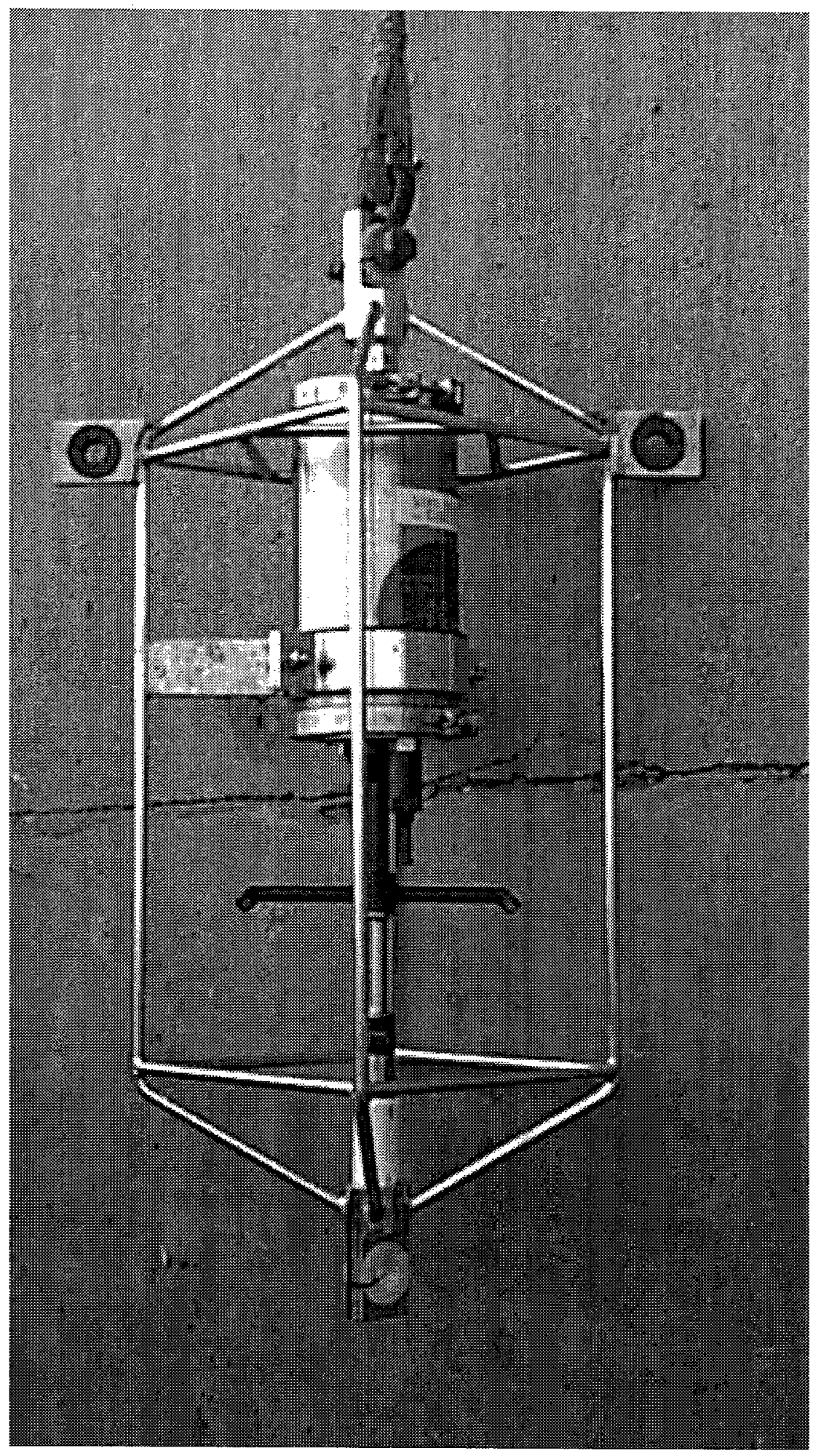

Figure 4: Photograph of the modified cage used with the FSI 3D-ACM. 


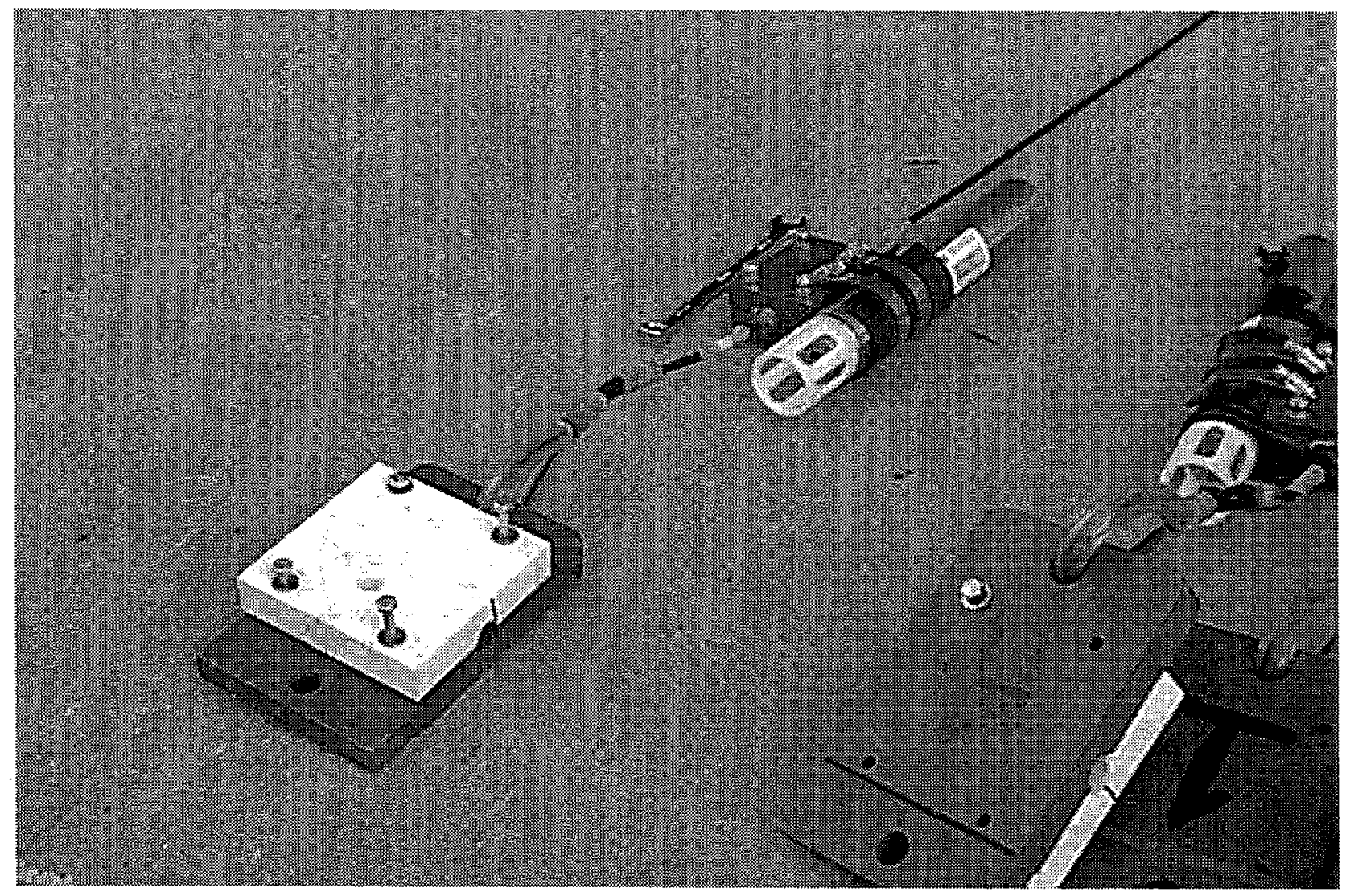

Figure 5: Photograph of the clamp used to attach the vertical strings to the horizontal wire. 
vertical string showing the PVC clamping plates and a temperature recorder. Figure 6 (a) and (b) are schematics of the PVC clamping plates used to attach a vertical string to the horizontal member. A short (5-inch) piece of 1/2-inch tygon tubing slit lengthwise was placed over the horizontal wire at the desired clamping location. The horizontal wire was then laid in the machined groove and four $1 / 4 \times 20$ bolts compressed the plates, clamping the PVC blocks to the wire. The use of four $1 / 4 \times 20$ bolts with associated flat and lock washers and nut that had to be assembled on deck did not present a problem during the August 1998 deployment due to the calm seas; however, it would have been a challenge had the sea state been higher. This clamping assembly provided mid-wire attachment points. It was from these sites that the vertical strings were hung.

The vertical strings were made of $3 / 16$-inch diameter $3 \times 19$ jacketed wire rope. They were mated to the PVC clamp in advance by passing the wire through a hole in the clamp plate and forming an eye by nicopressing the wire back onto itself. No thimble was used in the eye. Chafe protection to the wire was provided around the eye by a length of tygon tubing that had been threaded onto the wire prior to forming the eye.

Each vertical string had five Sea-Bird SBE-39 temperature recording instruments and one Brancker Research, Ltd., pressure and temperature instrument. The instruments were clamped to the vertical wire using the assembly shown in Figure 7. Figure 8 is a schematic of one half of the clamp used with the temperature recorders. As before, two PVC plates were machined with a groove and clamped around the wire using four $1 / 4 \times 20$ bolts. One vertical end of the PVC blocks was radiused to accept the cylindrical shaped instruments. The instruments were secured to the PVC blocks with two hose clamps that passed around the instrument and through two machined slots in the blocks. At the bottom of each vertical string was a cast iron sash weight that, on average, weighed 78 pounds (dry). The weight was used to minimize the horizontal excursion of the bottom of the vertical string.

The central vertical string was different from the other four described above. Unlike the others, it was shackled directly to the bottom bale of the FSI 3D ACM located in the center of the horizontal member. Not only was it attached differently but it also had a different complement of instruments, which had their own clamping mechanism. The central vertical string was made from 3/16-inch diameter $3 \times 19$ jacketed wire rope. The instrumentation deployed on this vertical string included five Sea-Bird MicroCATs (model SBE-37LM). The MicroCATs were clamped to the wire using the clamping mechanism supplied by the manufacturer provided with instruments with inductive modems. Although the data from these instruments was not transmitted inductively up the wire, the clamping mechanism was utilized. A 61-pound (dry) cast iron sash weight was shackled into an eye at the bottom of the vertical string. 


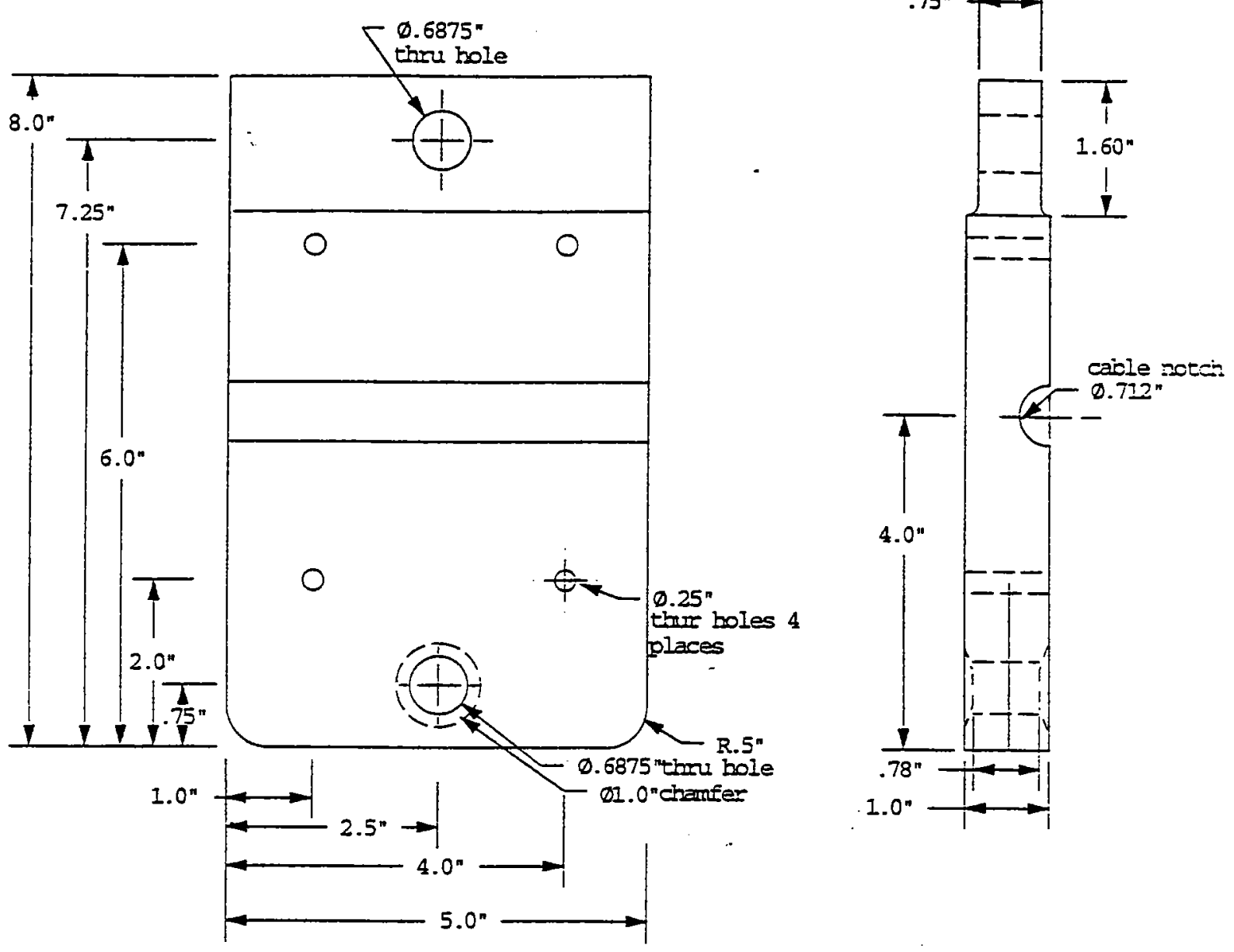

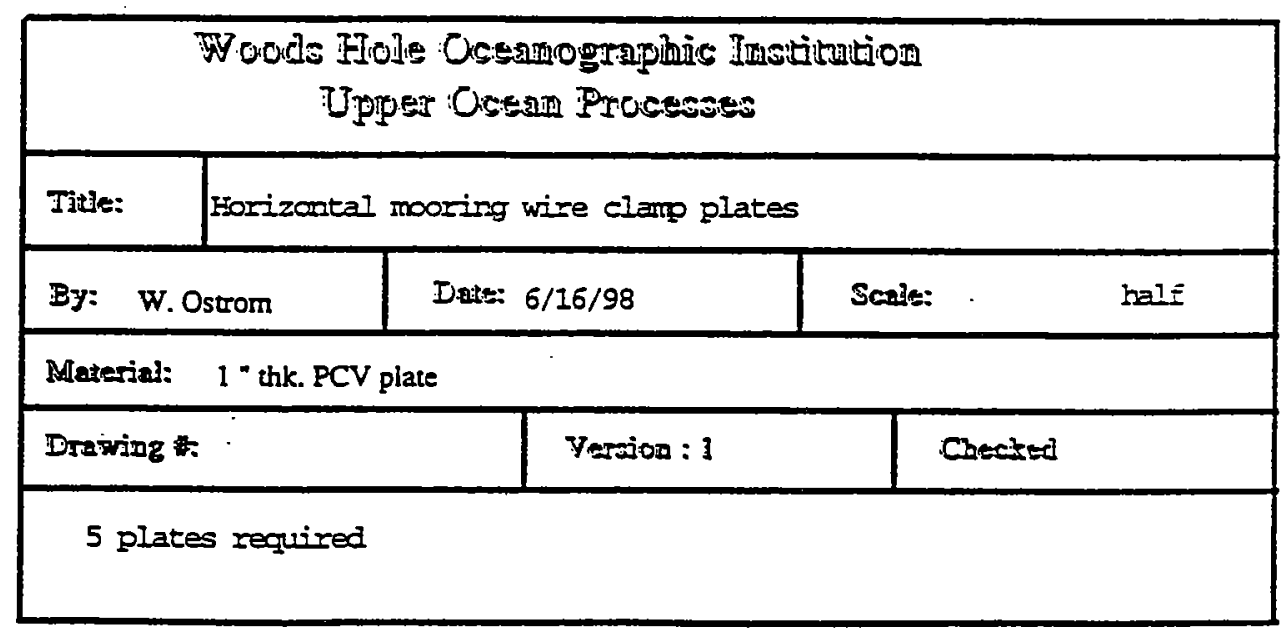

Figure 6: (a) Horizontal mooring wire clamp plates. 


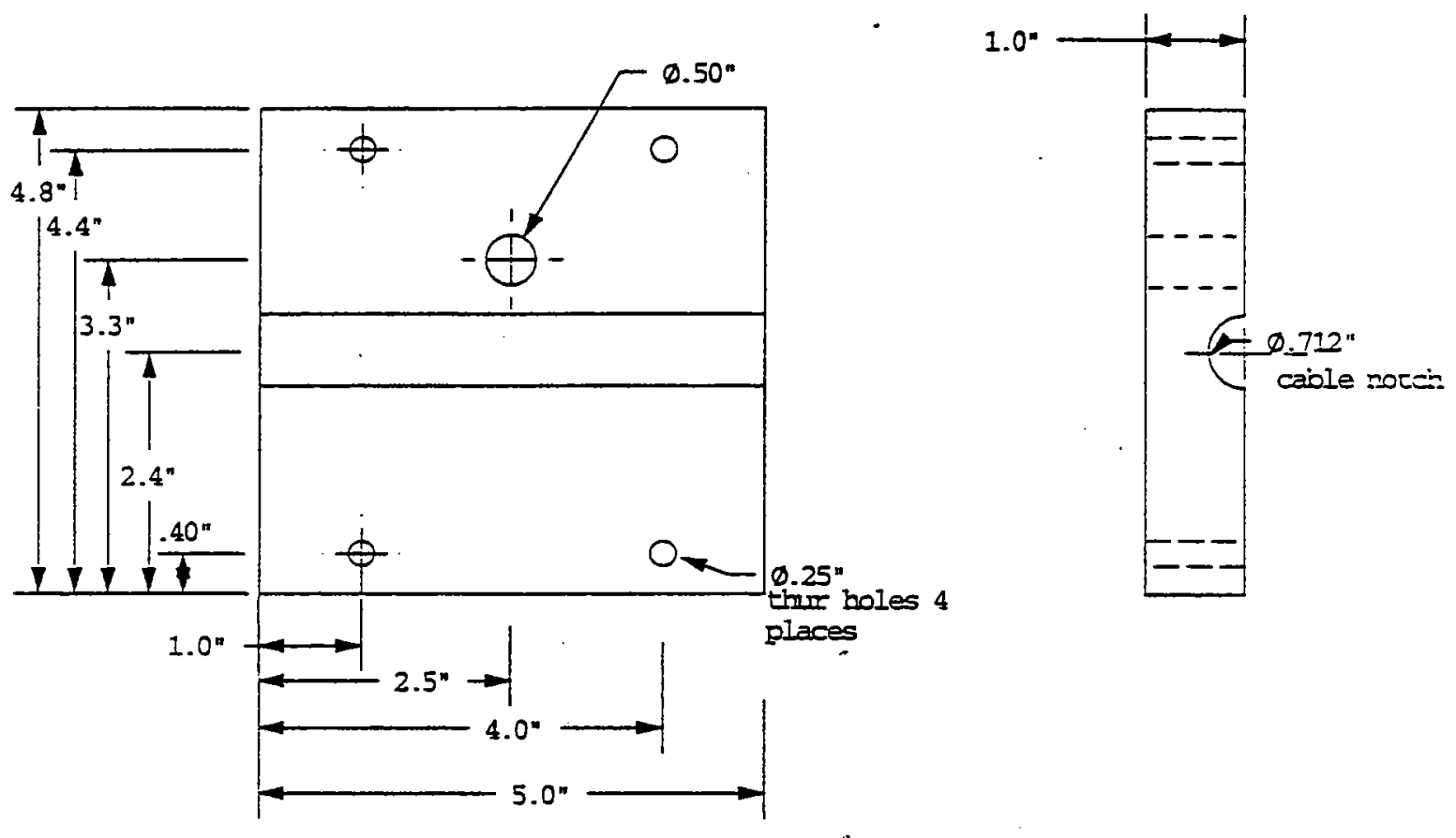

Woods IIols Ocenmograplinic Imetivation

Upper Ocean Processec

Title: $\quad$ Forizantal mooring wire clamp backing plate

\begin{tabular}{|l|l|ll}
\hline By: W. Ostrom & Date: 6/16/98 & Scale: & half \\
\hline
\end{tabular}

Mlaterial: 1 * thk. PCV plate

\begin{tabular}{|c|c|}
\hline Irrg prige & Yarsion: 1 \\
\hline
\end{tabular}

23 plates required

Figure 6: (b) Horizontal mooring wire clamp backing plate. 


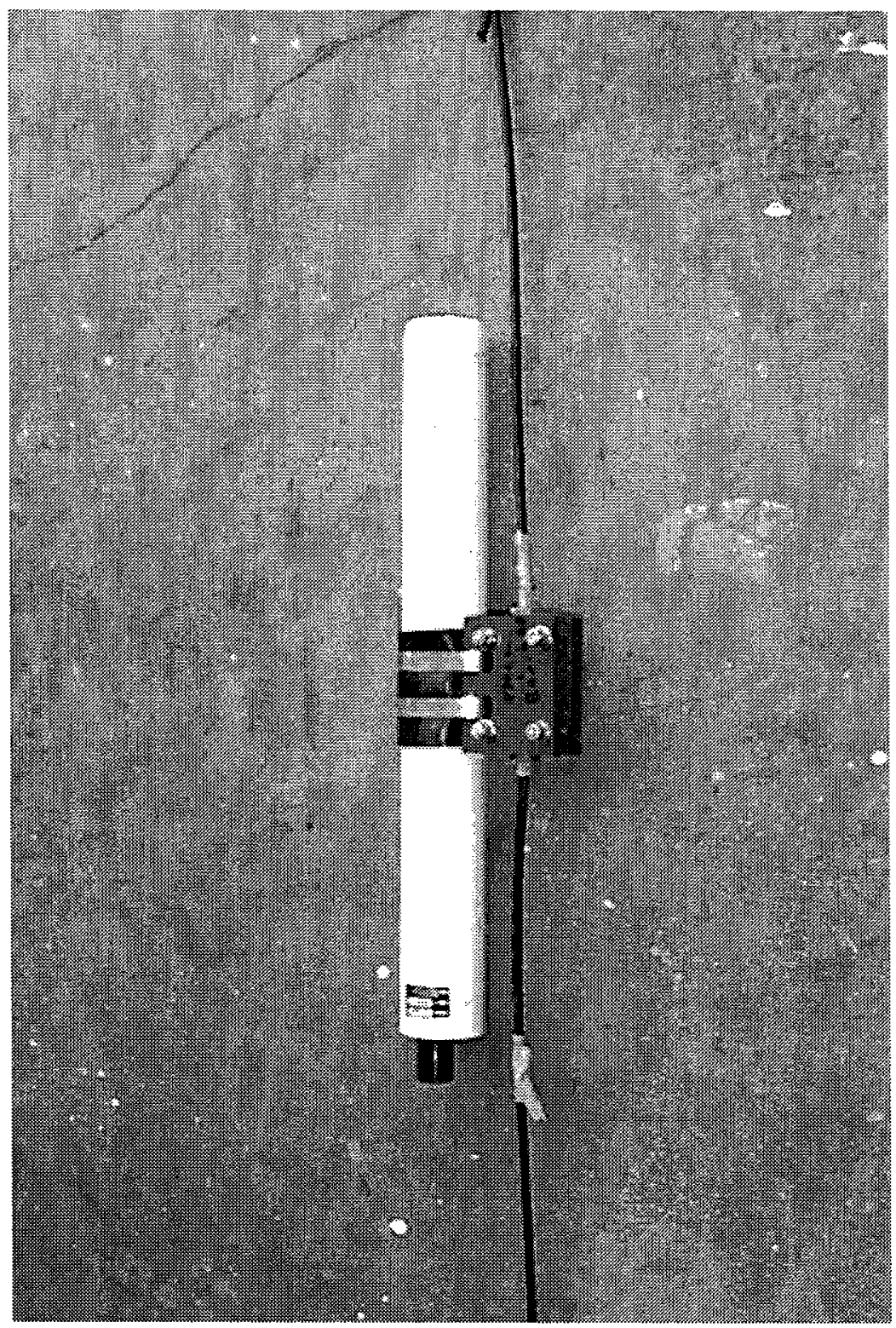

Figure 7: Photograph of the clamp attaching the temperature recorder to the vertical instrument string. 

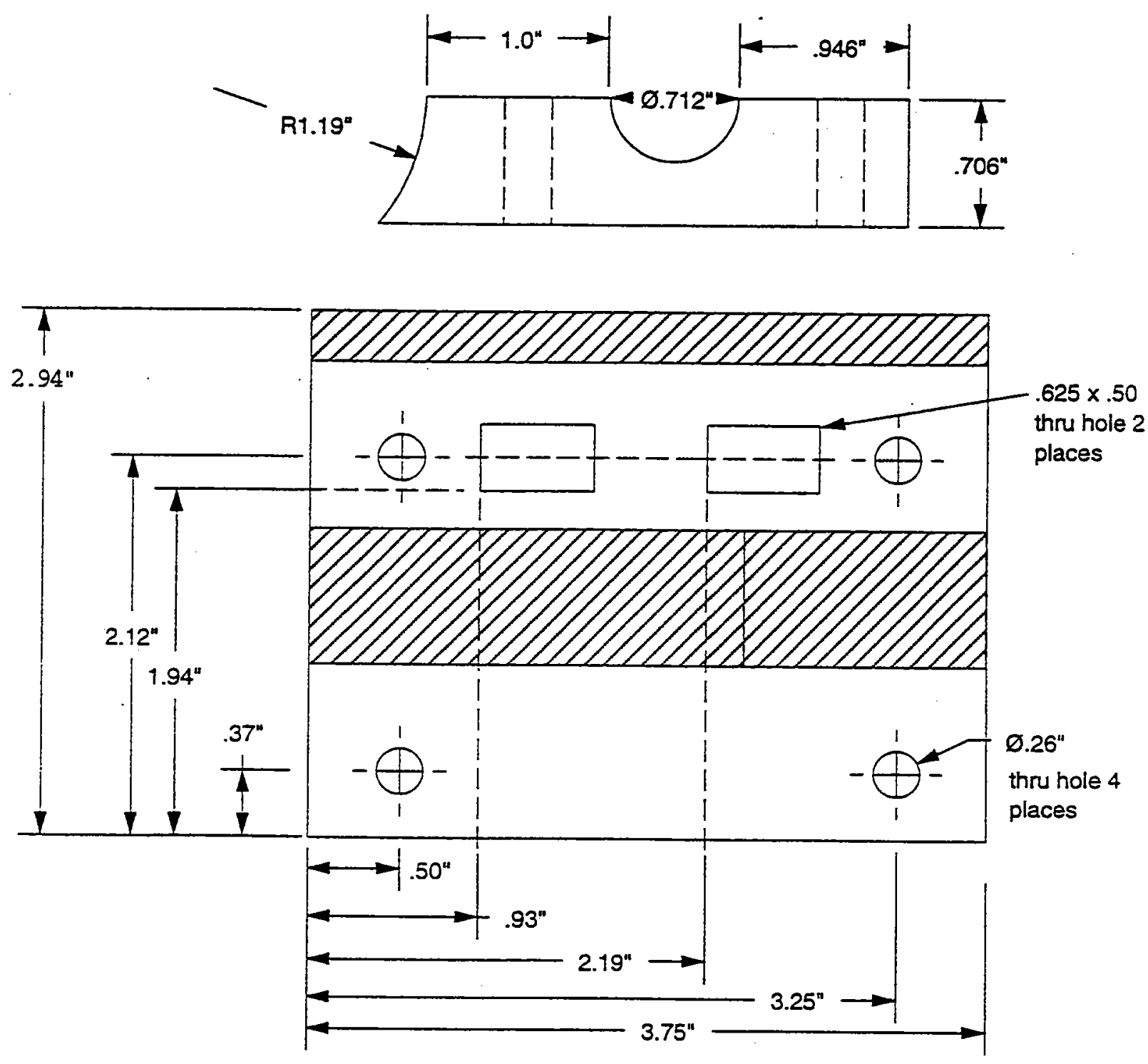

Figure 8: Schematic of temperature recorder wire clamps.

\section{B. Supplemental Buoyancy}

Supplemental buoyancy was provided at each element deployed along the horizontal member to offset their weight. The two FSI current meters at either end of the horizontal array each had two plastic Panther Plast floats (product number 629) which were 9 inches in diameter and provided 8.8 pounds of buoyancy each. A short length of nylon line was passed through 
the molded lugs in the floats as shown in Figure 9 and shackled to the top bale of the current meter cage.

The FSI 3D-ACM deployed in the center of the horizontal member required a pair of 17-inch diameter glass balls for supplemental buoyancy. The glass balls were attached to a two meter-long shot of wire that was shackled into the top bale of the current meter cage. The wire was terminated with a nicopressed eye with thimble. The clamp used with the glass balls is shown in Figure 10. It consists of two backing plates from the clamps used to attach the vertical strings to the horizontal member as shown in Figure 6. The two mating PVC plates were bolted to the plastic hard hat of the glass ball using a single $3 / 8$-inch diameter bolt and large washers on one side of a wire groove in the PVC. Two $1 / 4 \times 20$ bolts were used on the other side of the wire groove to compress the plates against the wire. One clamp was used per glass ball.

The other four vertical strings also had two 17-inch diameter glass balls that were clamped to a short length of wire ( 2 meters). The wire was terminated with a nicopressed eye and shackled into the top of the PVC clamp on the horizontal wire.

\section{Anchoring System}

Maintaining the position of the horizontal mooring anchors after deployment is a critical requirement. Dragging anchors would shorten the distance between the two anchors and position the horizontal array at less water depth or bring it to the sea surface. The exposure to surface waves would most likely damage the instrumentation and compromise the recorded data.

\section{Anchoring Tests}

Several field tests were conducted in 1997 to determine the holding capability of three types of anchors prior to the horizontal mooring deployment. A cast iron Dome-topped cylindrical anchor was tested along with a Mace anchor (deadweight cast iron cylinder with steel skiffs on the bottom) (Figure 11). A new anchor type from DorMor ${ }^{\circledR}$, Inc., was the third design tested. This is a pyramid-shaped cast iron unit with a holding stem (Figure 12). The anchors were towed along the bottom with the towline pulling at 45 degrees and at 30 degrees relative to the sandy floor of Vineyard Sound (Figure 13). The anchors responded with a typical slip-stick response to applied anchor line loads. At the higher slip force the anchor breaks out of the sand and is dragged towards the towing vessel, until the anchor line load is low enough so that the anchor buries itself again and is holding. Once the line load has increased to the slip tension, the anchor breaks out of the sandy ground again in a self-repeating process. The holding tensions did not change when the angle between the anchor line and the seafloor was decreased from 45 to 20 degrees. The line tensions were monitored with a load cell. Table 2 shows the results from the anchor pull tests. 


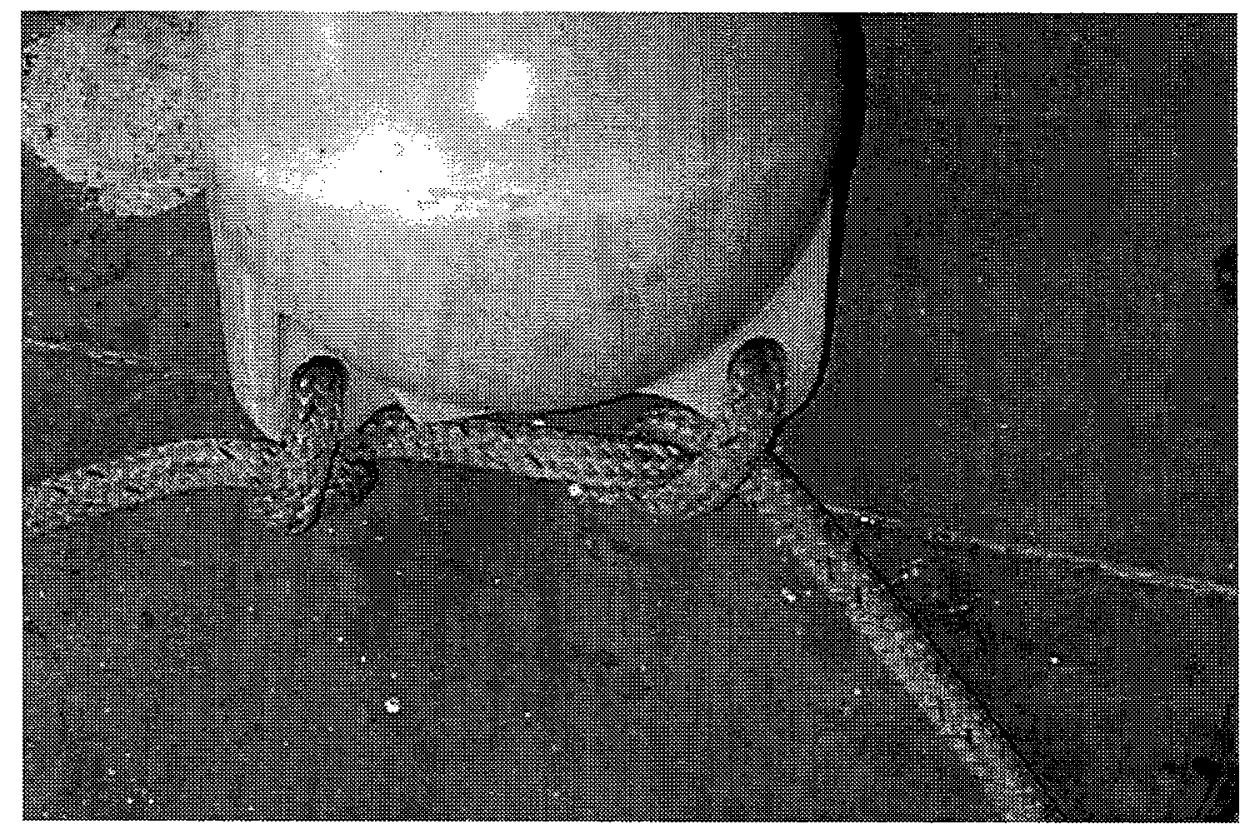

Figure 9: Photograph of attachment of Panther Plast floats.

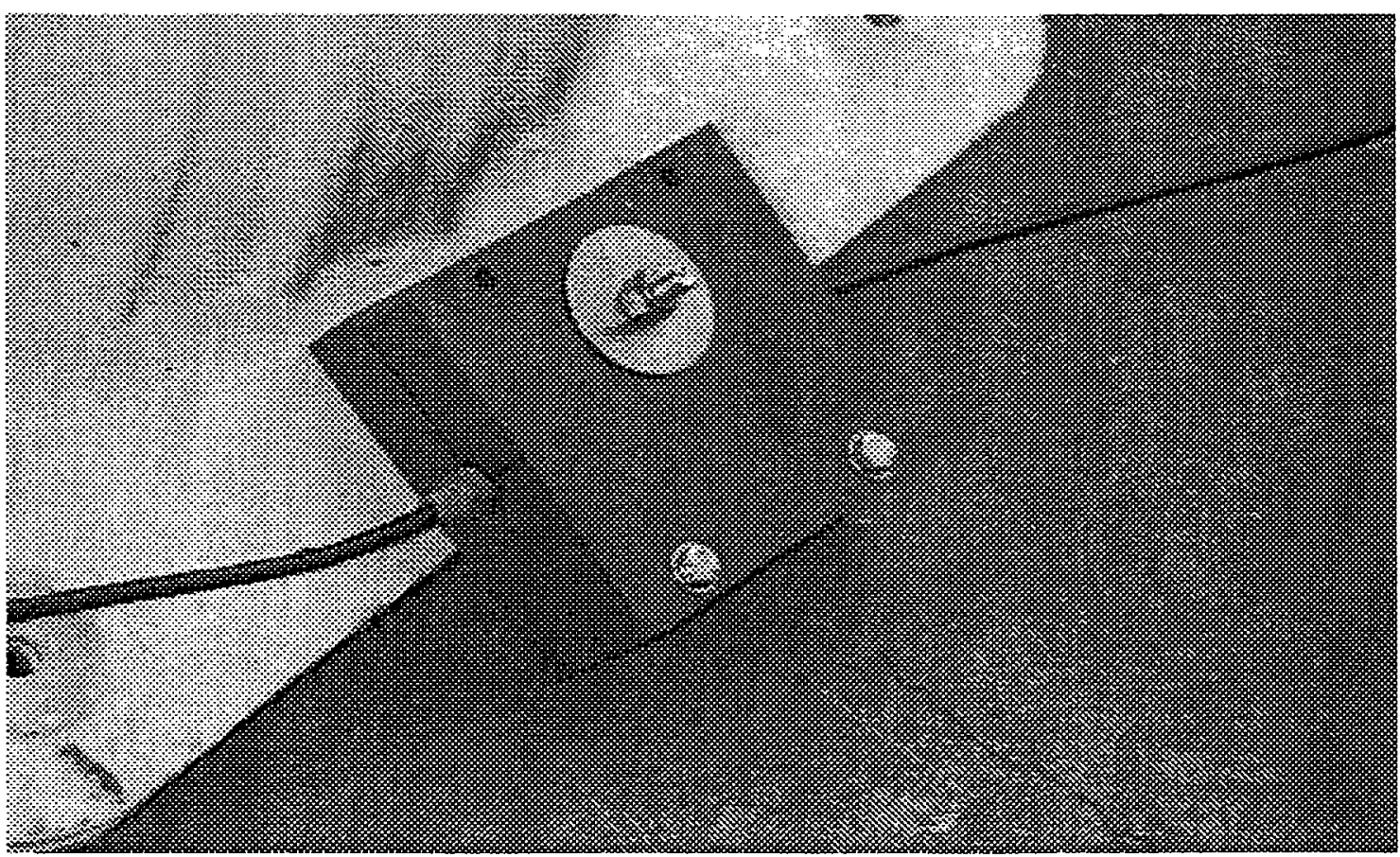

Figure 10: Clamp used to attach 17-inch glass balls to wire rope for supplemental buoyancy. 

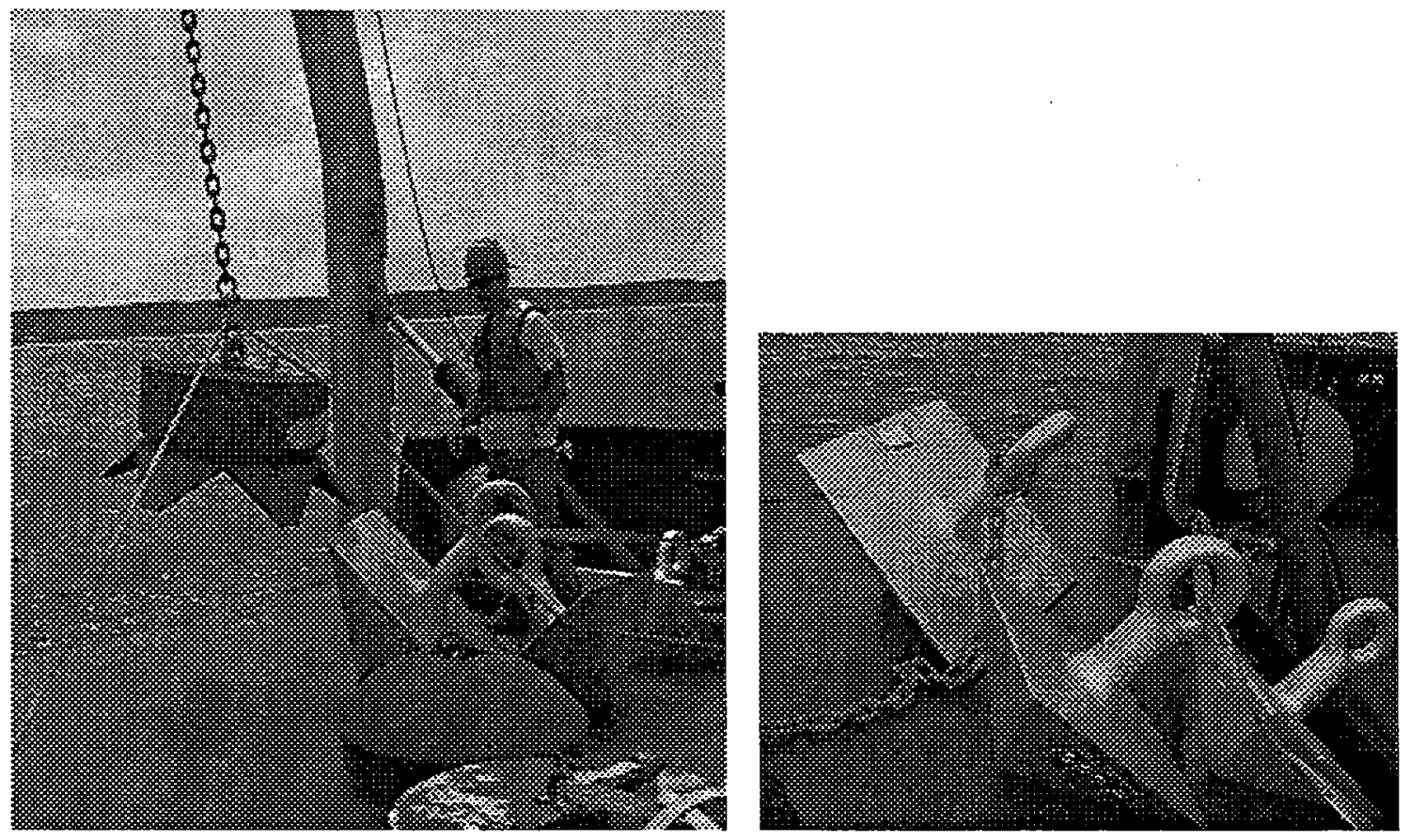

Figure 11: Anchors tested for the horizontal mooring. Figure 12: Photo of three DorMor® anchors.

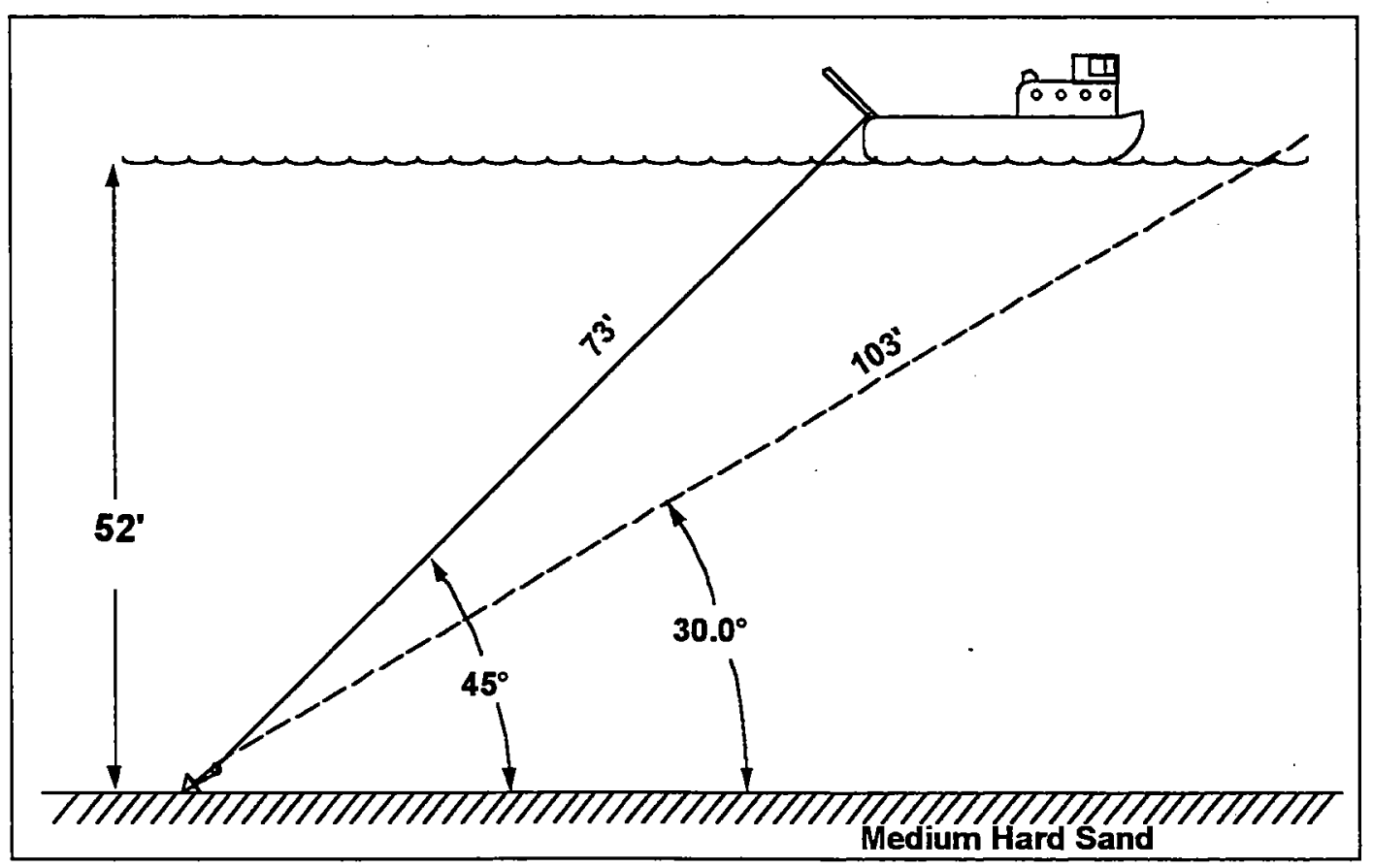

Figure 13: A schematic showing the configuration of the anchor holding tests. 
Table 2: Anchor holding test results

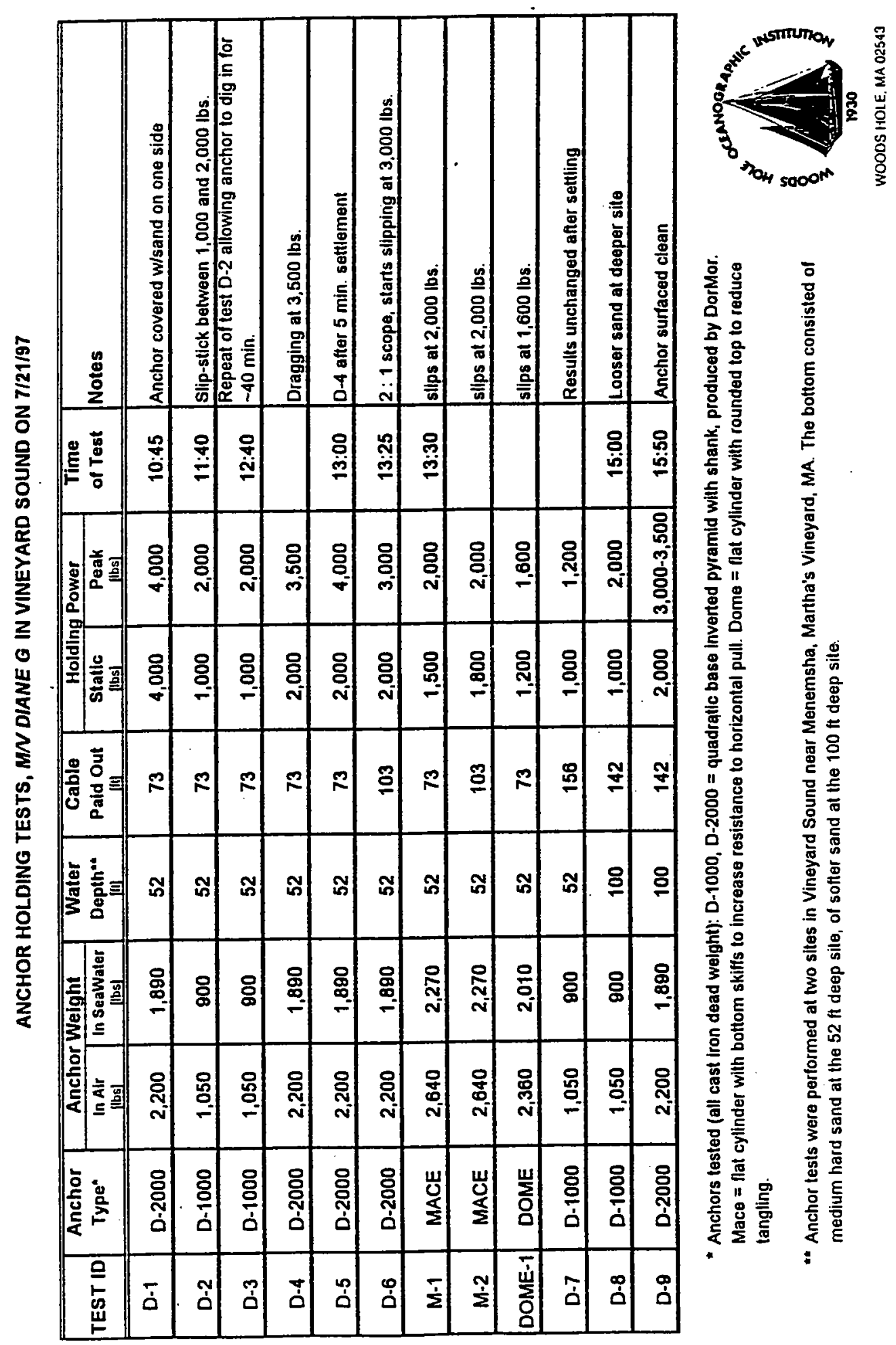




\section{Test Results}

The anchor holding power expressed as a fraction of the anchor weight was determined as the minimum anchor arresting force (stick force) measured. The DorMor $®$ holding power was equal to its submerged weight, the Mace anchor holding tension was 66 to 79 percent of its weight, and the Dome anchor was 59 percent of its submerged weight. The higher slip

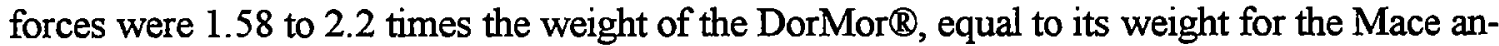
chor and 80 percent of its weight for the Dome anchor. The DorMor $\circledast$ anchor was selected to secure the horizontal mooring. The proper sizing of anchors was most important in order not to lose the horizontal arrays in severe seas.

An additional drag test with a DorMor $®$ anchor was performed in March 1998 at a site with a soft muddy sea floor. The slip-stick response of the anchor was not observed. The anchor could be dragged smoothly at a tension equal to its weight without any jerking and sudden locking into the sea floor. This test triggered a search for optimized anchoring of a horizontal mooring with its significant vertical tension component in the anchor rope.

The offshore oil exploration industry is facing a similar threat in particular with anchoring the new deep water floating platforms and tanker-based Floating Production, Storage, and Off-loading (FPSO) units. These platform moorings are no longer relying on traditional drag embedment anchors with catenary moorings (Huang and Lee, 1998) (Chimisso et al., 1998) (Wanvik et al., 1998), but use a taut mooring with a anchor rope angle of $35^{\circ}$ to $45^{\circ}$ with the sea floor instead (similar to the horizontal mooring). The catenary moorings are much longer and, therefore, more costly. The significant vertical component of the anchor line tension requires a new anchoring method. The industry is now using suction pile anchors and Vertical Loaded Anchors (VLAs). VLAs are manufactured by Bruce in England and Vryhoff in The Netherlands and have very high holding power after being dragged for often 10 to 20 meters vertically into soft mud and clay. Large diameter polyester ropes with chain segments near the anchor and at the platform are used to provide the needed strength and compliance. Extensive geotechnical tests are performed to determine the undrained shear strength of the ocean floor at a future anchor site which is needed to design the size of suction pile anchors or VLAs. The VLAs require embedment drag loads of 40 to 50 percent of their ultimate holding power. The significant extra cost to secure anchors at a given location assure that the platforms stay on station under all weather and sea-state conditions.

\section{The Selected Anchor}

The DorMor@ anchor is a compromise candidate. Due to its concentrated steel mass, it may dig significantly into soft mud with time, thereby increasing its resistance to vertical lift. The local sea floor firmness at shallow-water, open-ocean sites needs to be tested under the effects of large surface waves. Large ripples can form in sandy sea bottoms due to wave action, which dislodge the upper sea floor layer, thereby destabilizing the anchor embedment. This effect should be somewhat limited at 100-meter water depths (Traykovski et al., submitted). The anchor holding force is critically dependent on the sea floor in which it is placed. Some of the procedures developed by the oil industry may need to be considered for long-term reliable station keeping of horizontal moorings. 


\section{Section 3: Instrumentation}

There were a total of 38 instruments deployed on the horizontal mooring. They included three current meters, one sphere-mounted motion sensing package, two acceleration recording instruments, eight instruments for measuring conductivity and temperature (three of which also measured pressure), 24 temperature recorders (four of which also measured pressure) and one acoustic release.

Appendix 1 lists all of the instruments that were deployed on the horizontal mooring. Within a particular instrument type, the instruments are sorted by serial number, vertical string, and depth (relative to the horizontal member) in Table Al-1. Table Al-2 also has the nominal $x$ and $z$ coordinates assigned to each instrument.

With the exception of the current meters, all the temperature sensing instruments were submerged in a cold bath at a known time before their deployment and after recovery in order to place a time mark in the data file. Appendix 2 lists the instruments and the times that they were placed in and removed from the cold bath prior to the deployment and following the recovery.

\section{A. FSI 3D-ACM}

Three FSI acoustic current meters (3D-ACM, s/n 1467, 1468, and 1469) were deployed along the horizontal member at a nominal depth of 20 meters. See Appendix 1 for grid location of the FSI current meters. The FSI current meters "measure velocity along four acoustic paths, three orthogonal magnetic vectors and two orthogonal gravity vectors (tilt) from which it calculates velocity relative to the earth", (FSI 3D-ACM Operating Instructions). The FSI current meters sampled vector-averaged north component of velocity, vector-averaged east component of velocity, vector-averaged up velocity component, vector-averaged tilt, instrument heading, instantaneous $x$ and $y$ tilt, instantaneous temperature and instantaneous pressure. The averaging interval was set for 90 seconds. No pressure data was obtained from s/n 1468 since the pressure sensor was inadvertently disconnected.

\section{B. Sea-Bird SBE-39}

The Sea-Bird SBE-39 temperature logger is a high-accuracy temperature recorder with internal battery and memory. The SBE-39s used on the horizontal mooring had sheathed thermistors, which, according to the manufacturer, have a time constant of approximately $0.7 \mathrm{sec}-$ onds. The instruments were powered by a lithium 9-volt battery, and they recorded instantaneous temperature data every 15 seconds. See Appendix 1 for the grid locations of the SBE-39 temperature loggers.

\section{Sea-Bird MicroCAT SBE-37 IM}

The SBE-37-IM MicroCAT is a high-accuracy, self-contained conductivity and temperature sensor (pressure optional) with an integral inductive modem for communication. The central vertical string of the horizontal mooring had four MicroCATs measuring conductivity 
and temperature; a fifth instrument measured conductivity, temperature and pressure at the bottom of the vertical string. The pressure sensor had a range of 0 to $100 \mathrm{psi}$. Instruments deployed on the central string did not utilize the inductive modem capability. However, the inductive modem clamping mechanism was used to secure the MicroCATs to the vertical wire. The MicroCATs recorded data every 15 seconds.

A MicroCAT measuring temperature, conductivity and pressure was mounted on each of the 48-inch diameter steel spheres to monitor sphere depth. A 30-meter long shot of 3/16inch diameter jacketed wire rope connected the MicroCAT to a surface float and was used to transmit data and receive commands. The float housed a Sea-Bird Electronics Inductive Modem Controller (IMC); an Onset Computer Corporation, Tattletale IV data controller / logger; and a Free Wave Technologies, Inc., wireless data transceiver along with the necessary battery power. The Tattletale IV would send a command to request a data sample from the MicroCAT through the IMC. Having received the pressure data from the MicroCAT, it was then sent to the wireless data transceiver for transmission in real time to a shipboard mounted transceiver. The depth of the spheres was monitored in real time as the ship tensioned the mooring. Details of the pressure telemetry system can be found in Appendix 3. See Appendix 1 for the grid locations of the SBE- 37 instruments.

\section{Brancker Research Ltd XL-200}

Brancker Research, Ltd., temperature and pressure loggers (model XL-200) were deployed at the bottom of the four outermost vertical strings. The temperature range was $-20^{\circ} \mathrm{C}$ to $50^{\circ} \mathrm{C}$ and the pressure range was 0 to $100 \mathrm{psi}$. The sample interval of the Brancker XL200s was 4 minutes.

\section{E. Motion Package}

The end buoy contained a Tattletale Model 6 controlled motion package consisting of three Systron Donner GyroChips, and a Columbia Triaxial accelerometer, model SA-307. The sensors were sampled for twenty minutes at the top of every hour. The sample rate was 12.5 $\mathrm{Hz}$. Data was written to an 800-MB hard disk at the conclusion of each sampling period. This instrument ran without problems during the 1998 Horizontal Mooring deployment.

\section{F. AxPacks}

The AxPacks, which were deployed near the opposite corner, at the bottom of the central string, and on one of the guard buoys, were small (approximately 8 inches long and 3 inches in diameter), light (air weight $1 \mathrm{~kg}$, near neutral in water), self-contained acceleration measuring instruments. The controller is an Onset Tattletale Model 8 mated to a Peripheral Issues Persistor CF8 compact flash device. The sensor is a Summit Instruments triaxial accelerometer (Model 34103A). The advantages of the 34103A accelerometers are its power supply requirements: a single $+5 \mathrm{~V}$ supply, drawing approximately $30 \mathrm{~mA}$, onboard anti-aliasing filters and ouput amplifiers, and a direct $0-5 \mathrm{~V}$ output signal, all in a cube smaller than one inch on a side. The combination of the Tattletale Model 8 and the Persistor CF8 allows large amounts of storage capacity (24-MB in the case of the AxPacks), low power consumption 
( 750 uA in hybernation mode, $\sim 30 \mathrm{~mA}$ while sampling), small form factor ( 2 " $\times 3 " \times 1 ")$, and easy data retrieval via the compact flash cards.

The AxPacks used the same sampling scheme as the larger motion packages, 20 minutes at the top of each hour. The AxPack sampling rate is $10 \mathrm{~Hz}$. All three AxPacks experienced premature failures during the deployment. Unit 1 ran for 91 hours, unit 2 for 33 hours, and unit 3 for 15 hours. These failures have since been traced to a problem with the hybernation routines in the Tattletale operating system. In laboratory testing, the failures were reproducable. After an upgrade to the operating system (which fixed unspecified hybernation bugs) the AxPacks successfully ran through a 24-day deployment cycle.

\section{Section 4: Deployment and Recovery Operations}

\section{A. Deployment}

In preparation for the deployment, the 44-meter shot of 3/8-inch wire rope was prewound onto the deployment winch drum. The first leg of the horizontal mooring to be deployed was that which contained the acoustic release. The 1000-pound DorMor® anchor was the first component to enter the water followed by the 3/4" chain and the 2000 -pound DorMor@ anchor. The steamer chain, 1/2-inch trawler chain, the acoustic release and the 15-meter shot of 1/2-inch trawler chain above it were lowered to the bottom using the 44-meter shot of 3/8-inch wire rope. During the lowering the jacket of the $3 / 8$-inch wire rope was damaged while on the winch drum when the heavy anchor load caused the wire to bury into the drum, tearing the plastic jacket.

Once the anchors had been lowered to the bottom the four 3/8-inch diameter wire rope shots that made up the horizontal element were pre-wound onto the winch drum. The first 48inch diameter steel sphere was attached to the mooring leg that had just been deployed and to the first wire shot $(B)$ of the horizontal member. The winch was used to lower the sphere into the water.

Just prior to deploying the sphere the surlyn pressure telemetry float was placed in the water and allowed to drift aft. The float housed the pressure telemetry electronics and was connected to the sphere by means of a 30-meter long shot of 3/16-inch diameter wire rope that passed through the inductive modem of a MicroCAT mounted to the top of the sphere. The ship slowly began to steam forward (ship speed approximately 1 knot) as the horizontal element was paid out.

Each of the vertical strings were pre-assembled with all instrumentation clamped to the wire and ready for deployment. At the first pre-marked vertical string location the PVC clamp was secured to the horizontal wire. The supplemental buoyancy provided by the two 17-inch diameter glass balls were attached to the top of the PVC clamp. The vertical string was deployed by hand, bottom end first. The 77-pound weight at the bottom of the string made it 
difficult to get a firm hand grasp of the small diameter wire without it slipping. The best holding points were the instrument attachments. The deployment procedure that eventually developed involved stretching the vertical string out on deck and protecting each instrument by having someone carry it to the stern where it was passed over the side. Each person shared the load of the vertical string as they walked the instruments aft.

With the first vertical string in the water, payout of the horizontal member continued. An FSI current meter was placed in line with the horizontal element between shots B and C. The mooring was stopped off using the Yale grip at the end of shot B while the current meter was attached in line. The current meter and supplemental buoyancy (two Panther Plast floats) were eased over the side and payout of shot $C$ continued. The second vertical string was deployed in much the same manner as the first. The second current meter located in the center of the horizontal member had a vertical string attached to the bottom bale of the current meter cage. The current meter was placed in line between shots $C$ and $D$. (The central vertical string had five MicroCAT instruments that measured temperature and conductivity, with the deepest instrument also measuring pressure. An acceleration sensing instrument [Ax Pack] was clamped to the deepest MicroCAT.) The vertical string was lowered into the water by hand using the technique described above. The current meter and supplemental buoyancy, consisting of two 17-inch diameter glass balls, were eased over the side and payout of wire shot D resumed. The remaining two vertical strings and current meter were deployed in the same manner as the others.

The surlyn foam float housing the second pressure data transmitter was lowered into the water from the starboard side just prior to deploying the second 48-inch diameter steel sphere. Once the steel sphere was deployed the surlyn float was cast off. The second sphere housed a motion package, which caused the sphere to be top heavy. In response to the weight of the motion package the sphere rolled so that the motion package and MicroCAT mounted to the top of the sphere ended up pointing downward while the sphere was on the surface. This created a potential problem involving the wire tether to the pressure data transmitter in the surlyn float. During the deployment, if the sphere had made a complete rotation, the wire tether would have become fouled on the underside of the sphere. Fortunately, as the mooring was tensioned, the sphere rotated back so that the wire did not become entangled. In the future some supplemental buoyancy may be needed on the sphere to keep it in the preferred orientation. Even if it is deployed without the motion package, the weight of the MicroCAT may be enough to cause the sphere to turn upside down if it is not outfitted with some supplemental buoyancy.

Following the deployment of the steel sphere the chain and wire rope of the second leg were deployed up to and including the 2000-pound DorMor $\$$ anchor. Before proceeding, a 120 -meter long 3/8-inch diameter wire rope ground line was wound onto the winch drum along with a second 120-meter shot. These shots of wire were used to lower the pair of DorMor(B) anchors to the bottom and would be used to tension the mooring. When the wire took the load of the two DorMor ${ }^{\circledR}$ anchors, the same problem that was experienced earlier with the wire burying into the drum occurred again. The winch also had difficulty holding the load even when the brake was applied. Once a lay of wire became buried the winch experienced snap loads each time the wire became freed, causing the winch to lurch on its mountings. The plastic jacket on the wire was damaged as it came off the winch but due to the high tensions the 
payout continued without stopping until the anchors were on the bottom. A 500-pound depressor weight was placed between the two 120 -meter shots and lowered to the bottom with the second wire shot.

With all the mooring components in the water, the mooring had to be tensioned in order to pull both spheres underwater to the appropriate depth. The tensioning was accomplished by having the ship pull on the ground line while monitoring the pressure data that was transmitted to the ship from the pressure telemetry floats. Pressure data from sphere number 17 could not be received due to a problem with the MicroCAT. The pressure data from sphere number 8 was, therefore, used to tension the mooring. While monitoring the pressure data the ship slowly steamed ahead. Due to the relatively slow sampling scheme of the MicroCAT, the pressure data was only updated every 15 seconds. The relatively slow output from the pressure instrument coupled with the momentum of the ship, which made it nearly impossible to quickly stop pulling on the mooring, resulted in overshooting the target depth of 20 meters. The pressure obtained at the conclusion of tensioning the mooring was $24.87 \mathrm{dbars}$. Satisfied with both the orientation of the array and the depth of the horizontal member as indicated by the pressure data from sphere number 8 , a marker can buoy was attached to the end of the tensioning wire shot and cast off.

The ship then recovered the pressure telemetry floats tethered to both spheres. The float was hauled on board and as much of the 3/16-inch wire tether was recovered before cutting the wire. Each tether (Figure 14) had an attached float located 12-meters from the MicroCAT in order to prevent the tether from fouling with the other instrumentation on the mooring following removal of the pressure telemetry floats.

The original plan was to recover the array backwards by hauling back on the wire rope used to tension the mooring. This would permit the recovery of the entire mooring including the DorMor $®$ anchors. The acoustic release deployed on the first leg of the array was intended as a backup recovery aid should the surface expression of the tensioning line be lost. A consequence of firing the acoustic release is that the anchors from that leg of the mooring would be left behind on the bottom.

\section{B. Recovery Operation}

Following the deployment cruise, alternatives were explored for using the same winch for recovery as had been used during the deployment. It was felt that the ship's winch would not be able to recover the anchors as had been originally planned, based on its performance during the deployment cruise. For a variety of reasons, including the availability of an alternate winch and the lack of adequate tie downs on the ship, a decision was made to use the ship's existing winch but to alter the recovery plan in order to utilize the winch's capabilities.

The recovery began by firing the acoustic release, which permitted both steel spheres to come to the surface. The ship then steamed to the sphere that was still connected to the anchors on the bottom and the sphere was recovered. The wire rope leading to the anchors was cut, freeing the horizontal mooring from the bottom. The ship could then maneuver in whatever direction was necessary, and the remainder of the mooring could be recovered easily. 


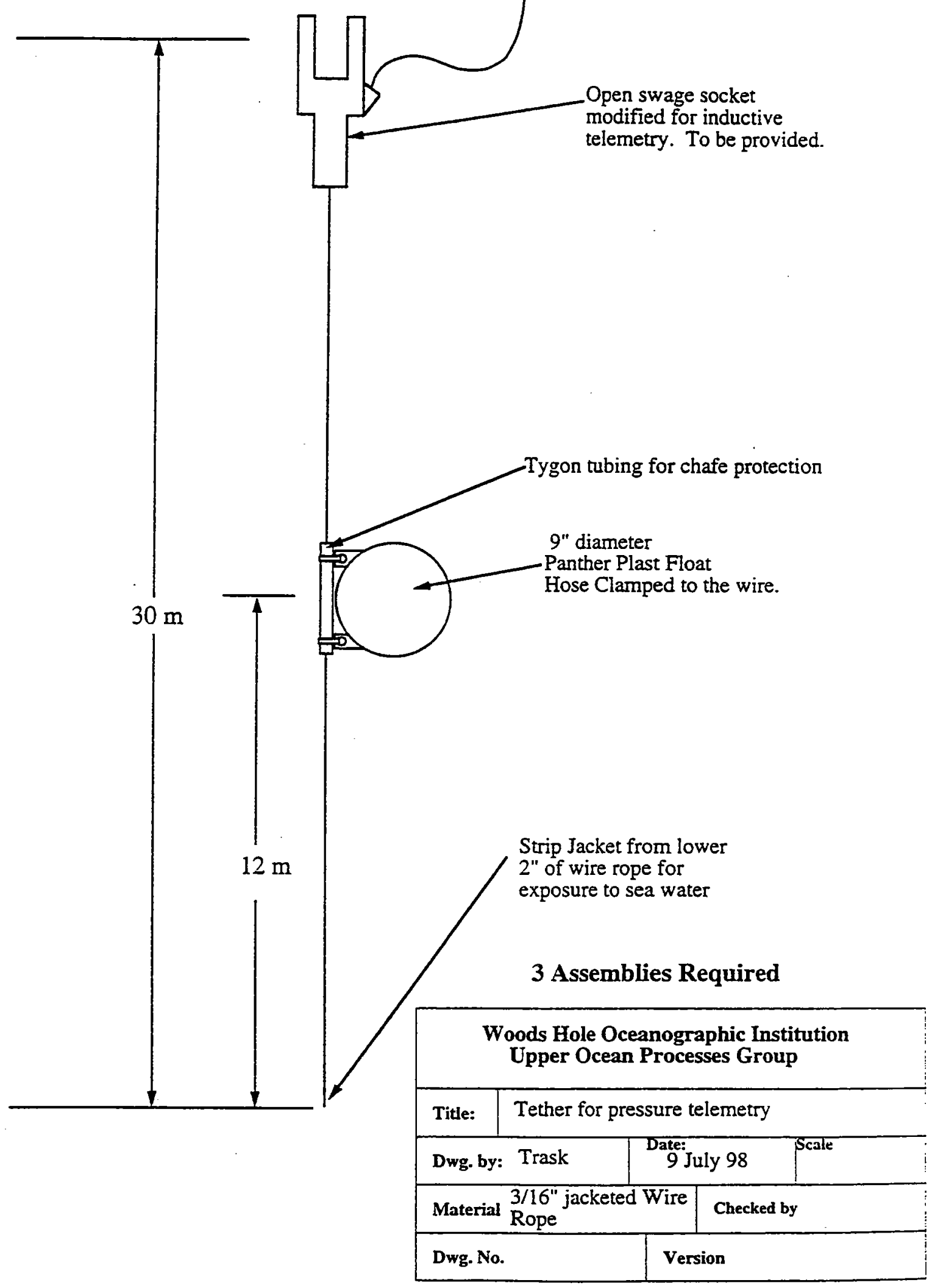

Figure 14: Pressure telemetry tether. 
The recovery of the horizontal member began from the sphere number 8 end and was the reverse operation of the deployment. The vertical strings were hauled out of the water by hand. Loops (approximately 12 inches in diameter) of dacron line (that was tied off on itself with a square knot) were looped around the vertical string instrument clamps. These provided a firm hold of the vertical strings that were a bit slimy after the month deployment. Each person had a loop and would wrap it around a clamp and walk the instrument forward. When the next instrument surfaced another person would loop their line around its clamp and walk it forward until all the instruments and depressor weight were out of the water. It may sound like stone-age oceanography but the loads were small, there were plenty of people to assist, and it worked well.

Of the two pairs of anchors that were left behind, one set still had the tensioning cable and marker can buoy attached. This left open the option of recovery at a later date should a ship be available with adequate hauling capability. The other set of anchors that were left on the bottom after firing the acoustic release would have to be recovered with a dragging operation, which is more time consuming and a more difficult task. The cost of recovery must be weighed with the replacement cost of the anchors. Recovery only becomes attractive when a ship is in the area for another project and there is time in the schedule to conduct the operation without adversely impacting the other project.

\section{Section 5: Array Performance}

In this section we present some preliminary results on the performance of the horizontal submerged array.

The array specifications called for the array to be aligned so that it was perpendicular to the crests of the solitons that transit across Stellwagen Basin from Stellwagen Bank. The specification was for the mooring to lie along a $60^{\circ}-240^{\circ}$ line, true. Thus, from leg 2 of the mooring, leg 1 would lie $60^{\circ}$ east of north. Figure 15 shows the anchor locations for the various instrumented platforms at the mooring site. The leg 1 anchor location was determined using GPS. A GPS position was obtained when the anchor was lowered to the bottom. The leg 2 position indicated is the ship's position as tension was released from the ground line following tensioning the moored array. This would not be the actual anchor location, but should be inline with the array at that time. The alignment with leg 1 determined from these positions is $60.8^{\circ}$ east of north. This alignment was confirmed by visual inspection of the telemetry floats remaining on the surface and from the ship's compass to within approximately $10^{\circ}$. We conservatively conclude that the array was aligned within $\pm 10^{\circ}$ of the desired location. A more accurate survey could have been done if we had recorded the GPS location and alignment of each telemetry float individually prior to its removal from the array. The 1.5 scope of the telemetry float tether would, however, still have introduced a degree of uncertainty.

The design goal was to have the instruments displaced by no more than \pm 2 meters from their design target depths. The design maximum current for this specification was 


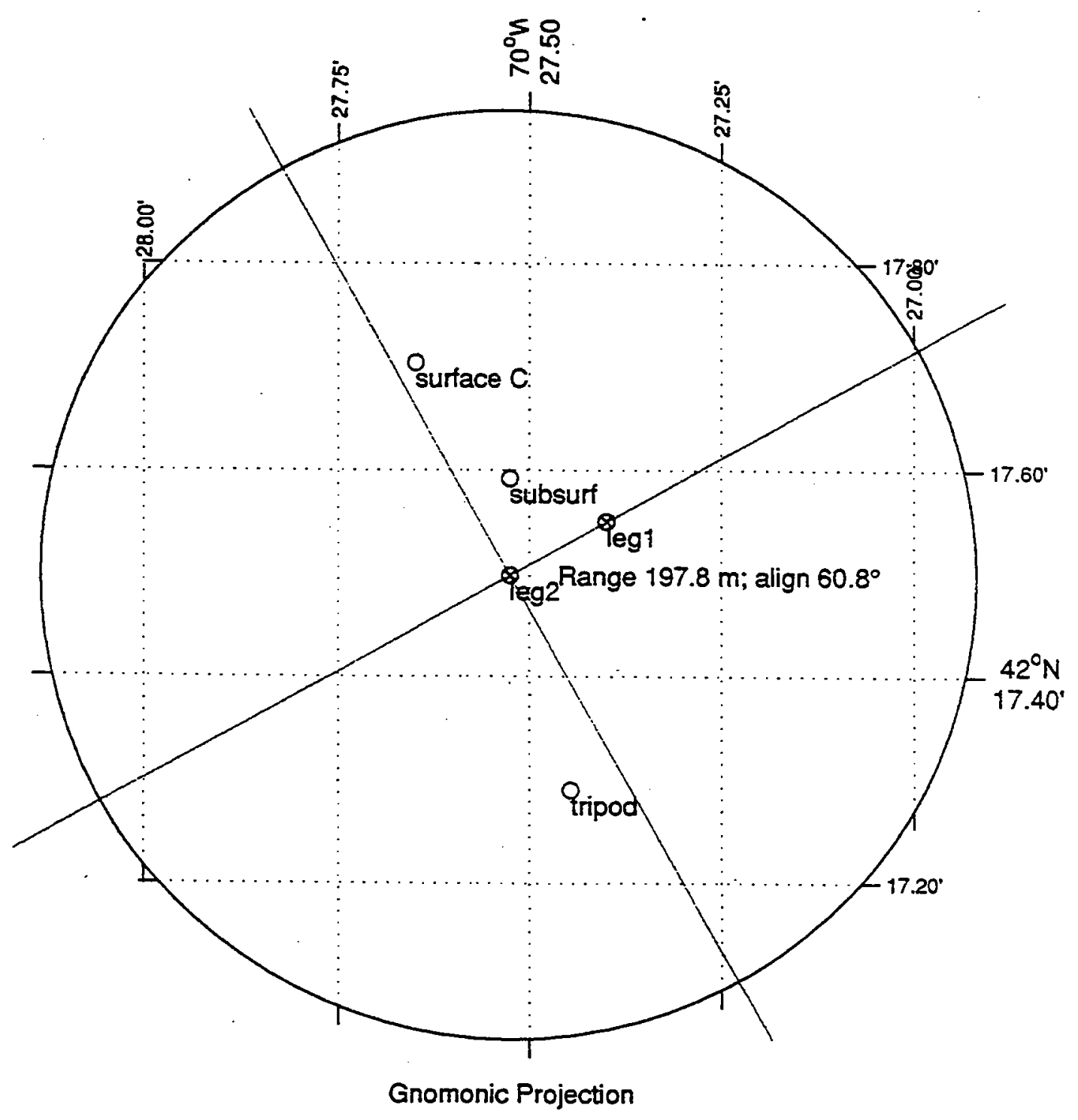

Figure 15: Anchor locations for instrumented platforms at mooring site. 
$100 \mathrm{~cm} / \mathrm{s}$. The survival current was specified as $300 \mathrm{~cm} / \mathrm{s}$. Figure 16 shows the statistics of the observed currents during the deployment. The data are from the United States Geological Survey (USGS) ADCP located on a tripod positioned approximately 200 meters south of the array. The ADCP provided a vertical profile of the horizontal currents every 2 minutes. Figure 16 shows the range, mean, and the quartiles (in gray boxes) of the current for each depth bin. The quartiles indicate that $50 \%$ of the time, the currents were located within the gray box indicated. The maximum observed currents were located in the depth range of the submerged array but did not exceed $100 \mathrm{~cm} / \mathrm{s}$. The east component of the current was larger and had more variability than the northern component. This is because the tidal currents were located mostly east-west.

The sensor locations were determined using the pressure measurements from the Brancker, SBE-39 and FSI instruments. The pressure record from a Sea-Bird tide gauge located on the anchor at a depth of 84-meters of a nearby subsurface mooring, monitored the local tidal elevation. This was subtracted from the sensor pressures as was an atmospheric bias determined from the time series just prior to the deployment of the instruments. This processing yielded a sensor position referenced to the bottom. Figure 17 shows the mean, range and quartiles for the sensor locations. The top figure (Figure 17a) shows the FSI instruments S/N 1467 and S/N 1469 located on the horizontal member and the Sea-Bird MicroCAT SBE-37 instrument, $\mathrm{S} / \mathrm{N} 670$, on sphere number 8 . The bottom figure (Figure $17 \mathrm{~b}$ ) shows the sensor locations at the bottom of each instrument string relative to the bottom.

The target depth for the top of the array was 20 meters (or 64 meters above the bottom.) The bottom of each string should be located 39 meters above the bottom. There appears to be a slight tilt or sag in the array with the eastern end approximately one meter deeper than the western side. The bottoms of the strings did not vary by much more than one meter from their mean locations. A larger range and variance is observed in the shallower pressure records. This is likely not due to mooring motion, but rather from aliasing of the pressure signal of surface gravity waves, which cannot be directly accounted for in this analysis. This signal decays exponentially and will have a much smaller affect on the lower sensors.

Figures $18 \mathrm{a}$ and $18 \mathrm{~b}$ show the locations of the bottom of the strings during the flood and ebb tides relative to their average positions. The flood tide was located nearly directly along the array while the ebb tide had some cross array component. The dominant motion appears to be that the motion of the ends of the array are incoherent. The depth of the upstream side of the array increases while the downstream side shoals. However, the range of motion associated with the tides does not appear to account for most of the variance in depth observed in Figure 17.

Figure 19 shows the locations of the bottom of the strings, relative to their average location, during a single soliton event on August 22. This single event lasted less than 15 minutes. However, the instruments were displaced by more than a meter from their nominal locations. The length of the array is well matched to the horizontal wavelength of the solitons we observed. The currents observed with these solitons were nearly $50 \mathrm{~cm} / \mathrm{s}$ and would reverse in direction over its wavelength. This can be seen in Figure 20, which shows the temperature and velocity records from the top of the array during the passage of several solitons. One leg of the array is encountering currents and drags that are incoherent from the other. This is resulting in 

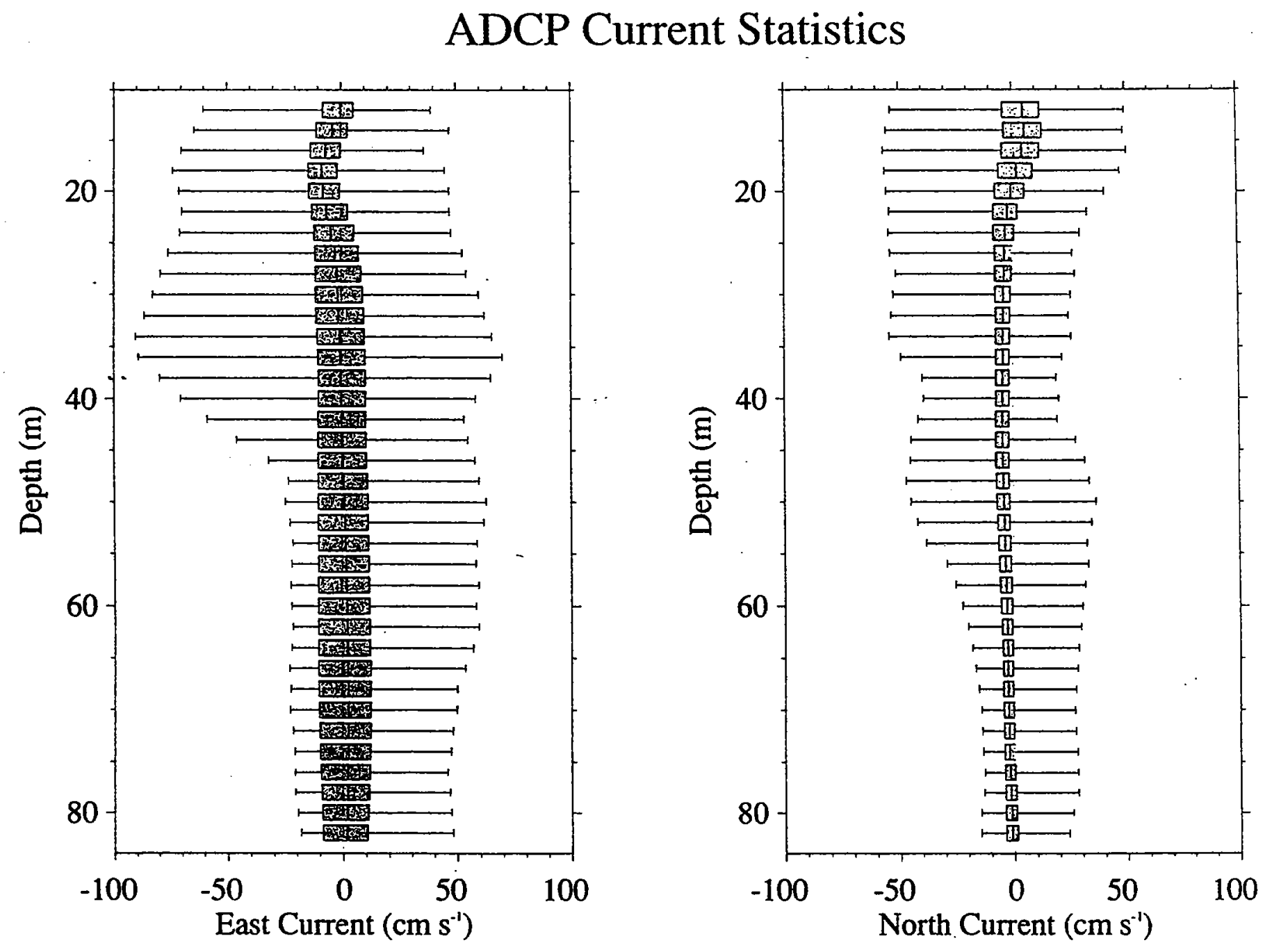

Figure 16: Range, mean and quartile of the currents. 


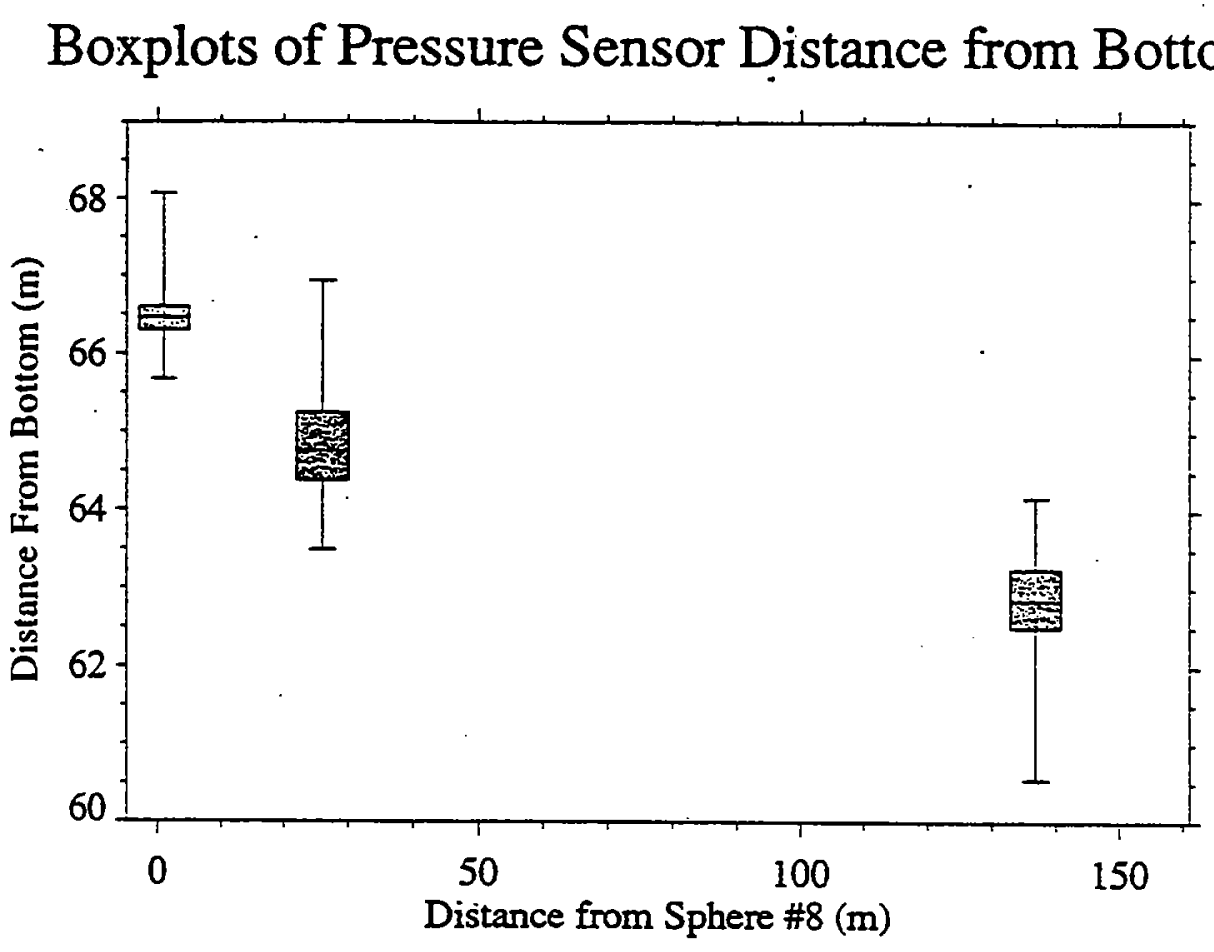

Figure 17: (a) Location of FSI instruments.

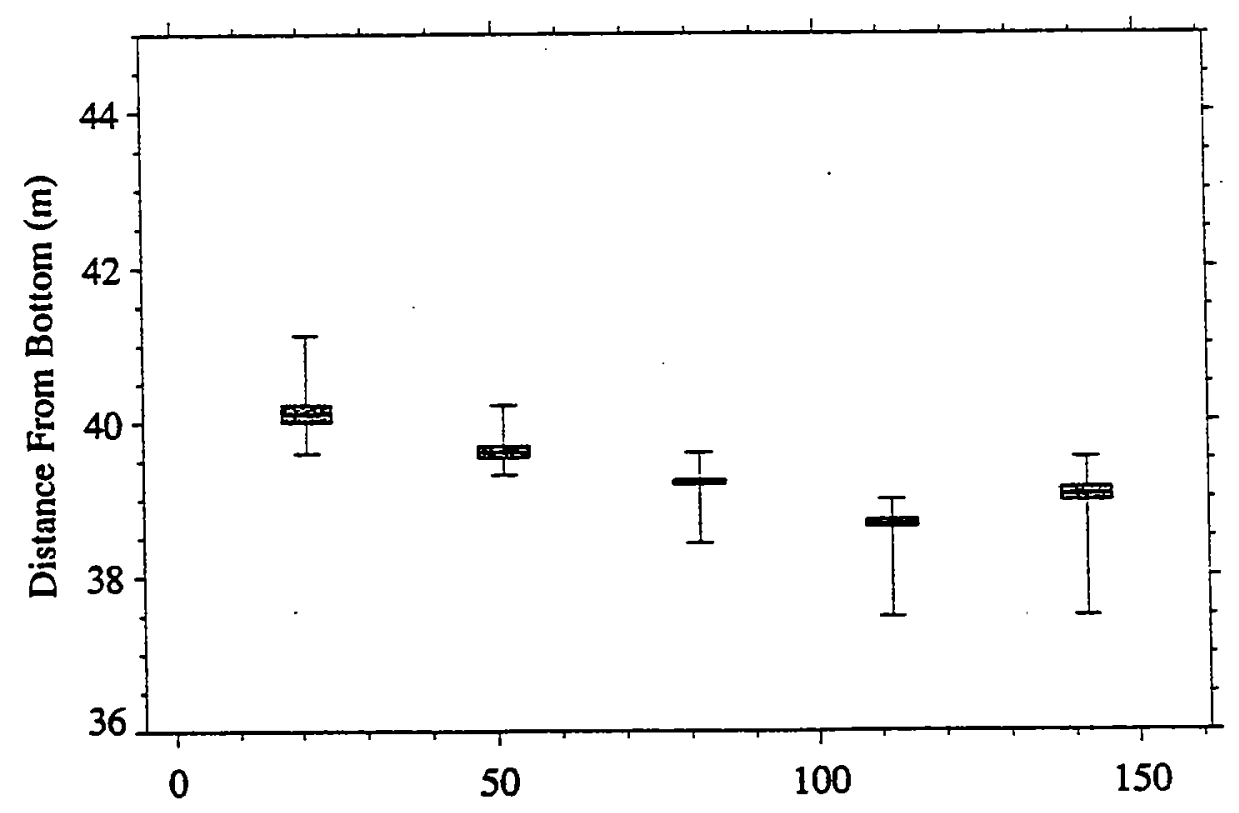

Figure 17: (b) Sensor locations at bottom of instrument strings. 


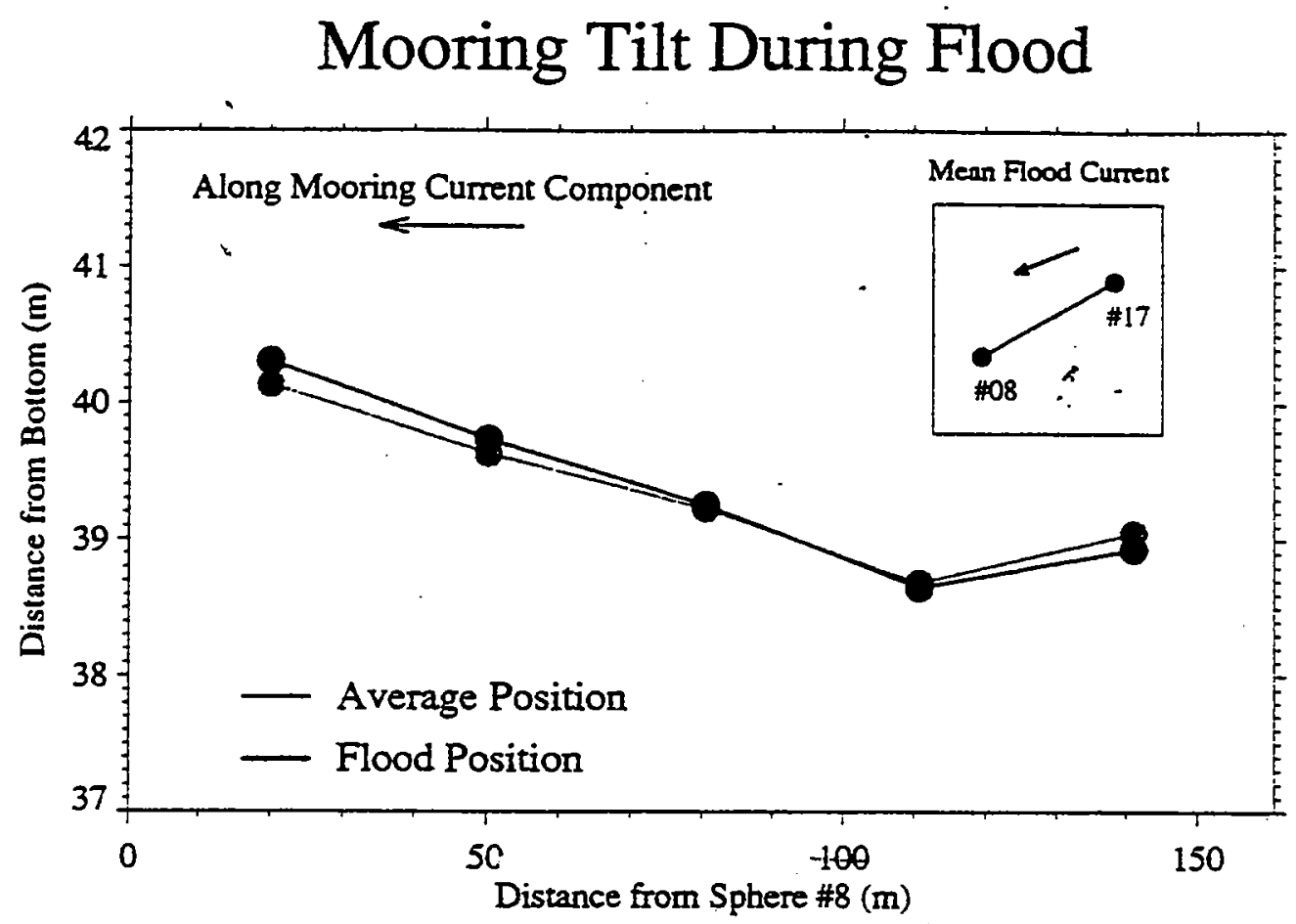

Figure 18: (a) Mooring tilt during flood.

Mooring Tilt During Ebb

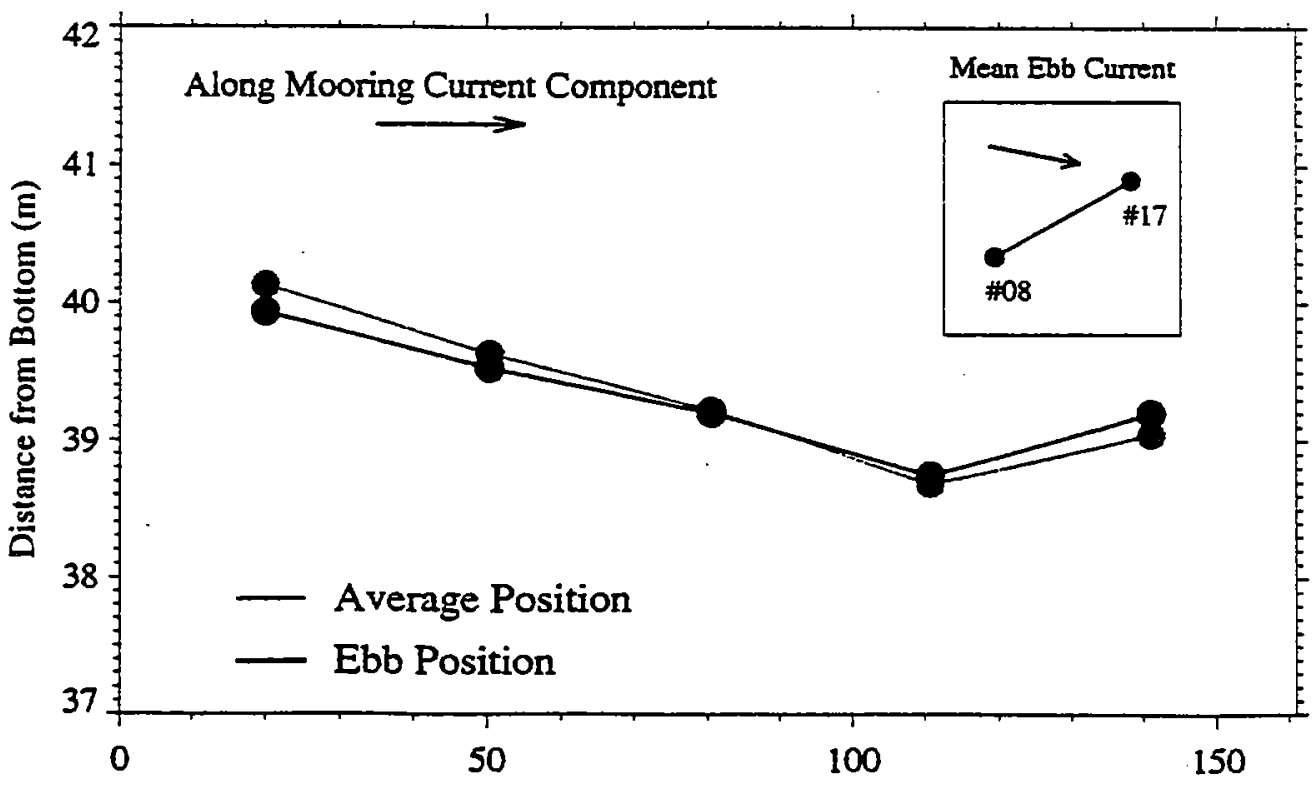

Figure 18: (b) Mooring tilt during ebb. 
Maximum Mooring Tilt During Soliton on 22 August

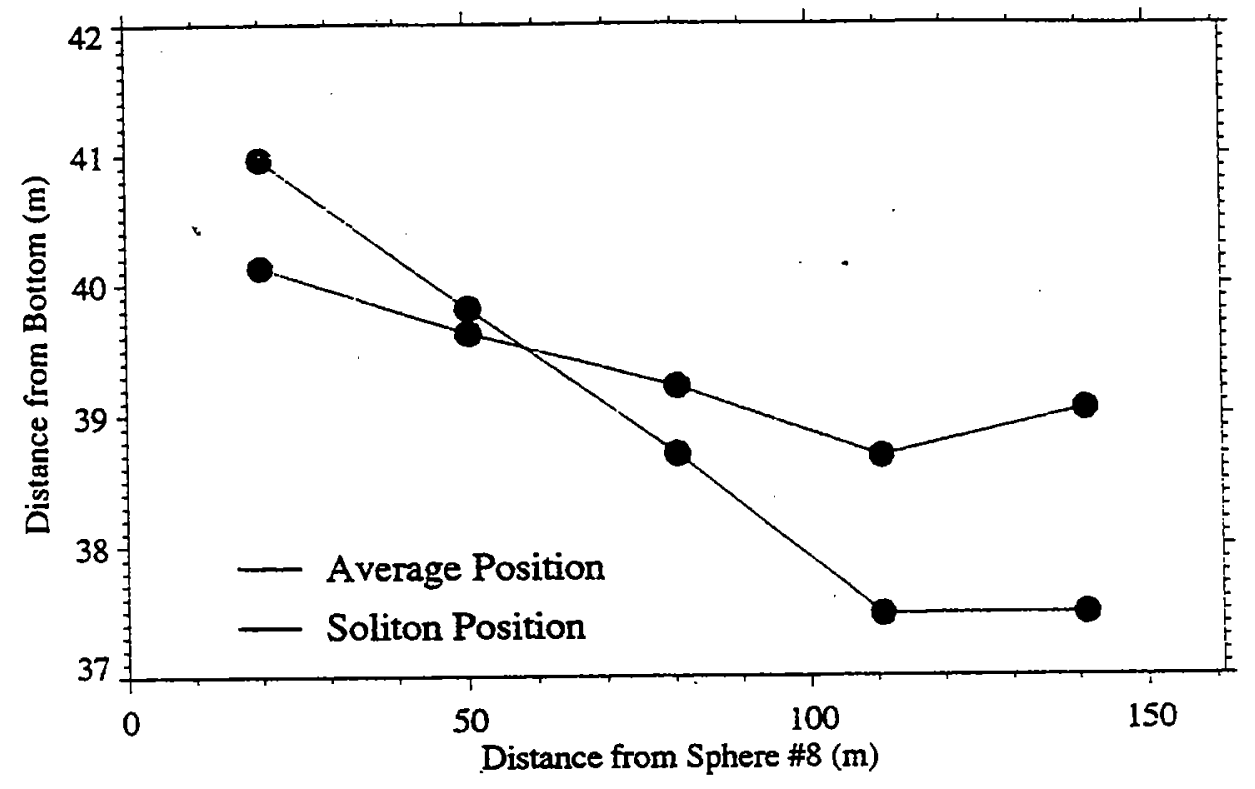

Figure 19: Maximum mooring tilt.
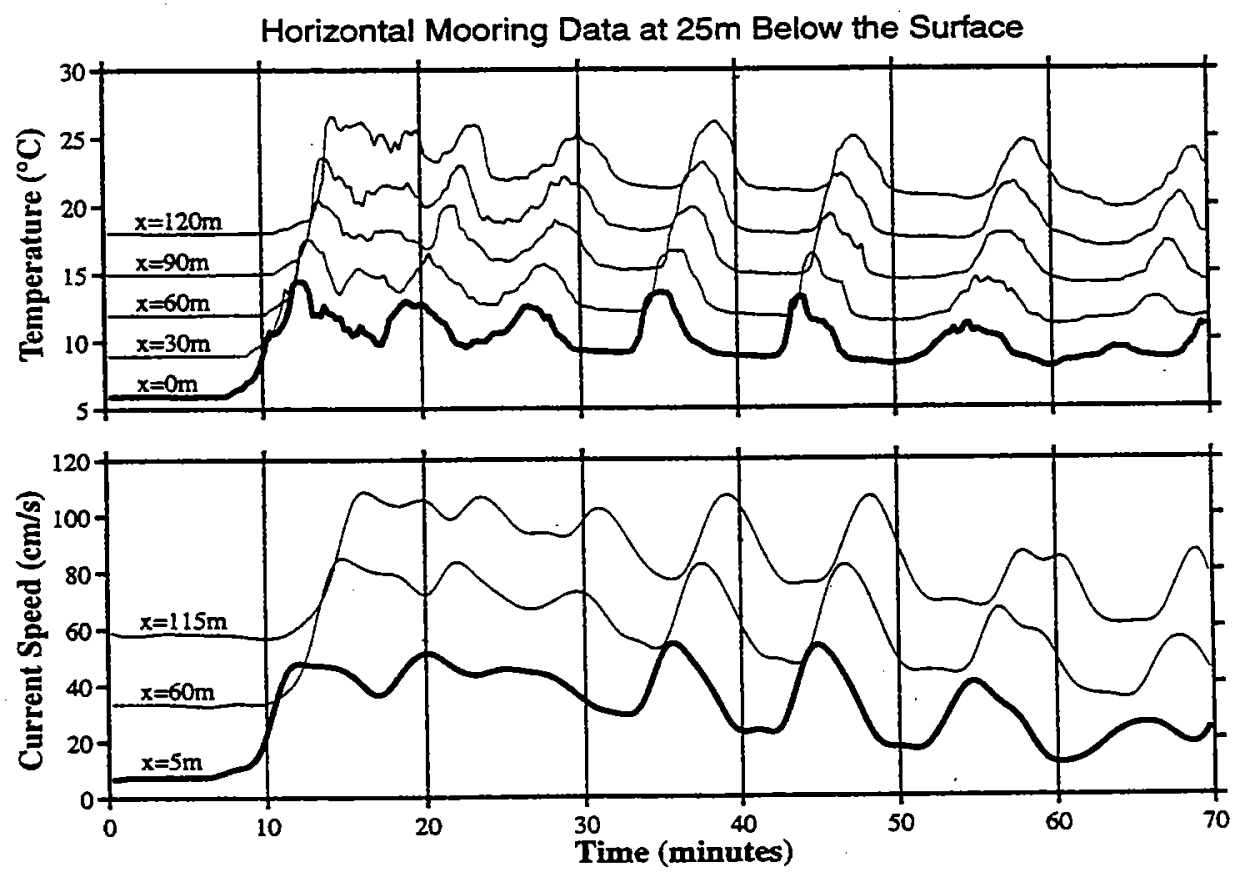

Figure 20: Horizontal mooring data at 25 meters. 
a dynamical mooring motion we had not encountered in our modeling studies that assumed that the currents were horizontally homogeneous across the array.

In conclusion, the submerged array was successfully deployed in the specified orientation and depth. There was an across-array tilt of approximately one meter over 120 meters. The tidal currents did not lead to significant mooring motion; however, further modeling is required to understand the motion of the array in response to solitons.

\section{Acknowledgments}

The captain and crew of the R/V Argo Maine deserve special mention for their assistance with the deployment and recovery of this unique mooring system. We also wish to thank Brad Butman, Jon Borden, Mark Baumgartner, Kent Bradshaw, Larry Costello and Jim MacConnell for their help at sea during the deployment and recovery operations. The guard moorings which surrounded and protected the horizontal mooring during its 27-day deployment were designed by George Tupper. Special thanks are extended to Dave Simoneau and the WHOI Mooring and Rigging Shop for their careful preparation of the complicated elements of the horizontal mooring. We sincerely thank Penny Foster for all her help in preparing this report. This work was supported by the Office of Naval Research Grant No. N00014-97-1-0158.

\section{References}

Chimisso, G., H. Tagher, N. C. Bliss, and G. Stan, 1998. Deepwater FPSO for Aquila Field Development in the Adriatic, OTC 1998 Proceedings, Vol. 2, OTC \#8808, Houston, Texas, May 1998, pp 259-267.

Falmouth Scientific, Inc., no date. Operating Instructions. 3-D Acoustic Current Meter, 3DACM, Version 6.0, Firmware Version 2.18. Falmouth Scientific, Inc., Cataumet, Massachusetts $02534,126 \mathrm{pp}$.

Gobat, J. I., M. A. Grosenbaugh, and M. S. Triantafyllou, 1997. WHOI Cable: Time Domain Numerical Simulation of Moored and Towed Oceanographic Systems, Woods Hole Oceanographic Institution Technical Report No. WHOI-97-15, 103 pp.

Huang, K., and M-Y Lee, 1998. Experiences in Classification of Deepwater Mooring Systems for Floating Structures", OTC 1998 Proceedings, Vol. 2, OTC \#8772, Houston, Texas, May 1998, pp 227-236.

Traykovski, P., J. D. Irish, and J. F. Lynch, Geometry, Migration, and Evolution of Wave Orbital Ripples at LEO-15, Journal of Geophysical Research, submitted.

Wanvik, L., L. Poldervaart, and H. Mong, 1998. FPSO with Turret Based Drilling System (FPDSO): An Approach to a Cost-Effective Deepwater Field Development, OTC 1998 Proceedings, Vol. 2, OTC \#8811, Houston, Texas, May 1998, pp 289303. 


\section{Appendix 1: Instrument Locations within the Horizontal Array}

Two techniques have been employed to describe the location of the instrumentation deployed on the horizontal mooring. The first references the vertical string number and depth with respect to the horizontal member. Figure Al-1 identifies the vertical string numbers and, for each instrument type and serial number, Table Al-1 identifies the vertical string on which it was deployed. This technique, though convenient, did not adequately describe the location of instruments that were not part of a vertical string.

The second technique utilizes a coordinate system whereby the reference for the horizontal axis ( $x$ axis) is sphere number 17 and the reference for the vertical axis $(z)$ is the sea surface. Instruments are located by their vertical and horizontal distances (in meters) from those reference points. Using this convention the coordinates of sphere number 8 are $(160.9,20)$. This indicates that sphere number 8 is nominally 160.9 meters from sphere number 17 and 20 meters below the sea surface. Figure Al-2 shows the coordinate system and Table A1-2 lists the coordinates of all instruments deployed on the two dimensional array. 


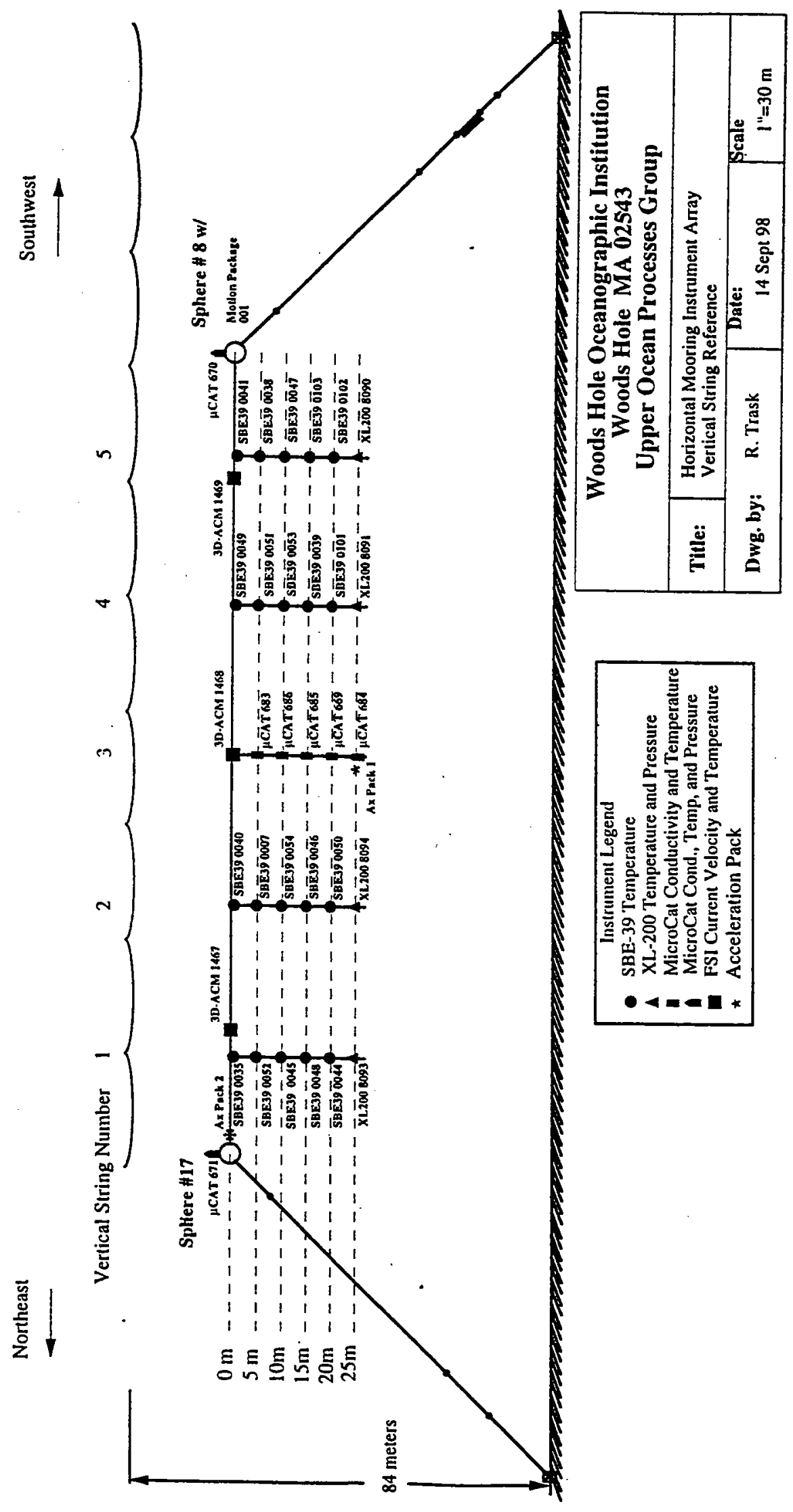

Figure A1-1: Vertical string numbers. 
Table A1-1: Instrument type and serial number

\section{Horizontal Mooring, August 1998}

Instrumentation

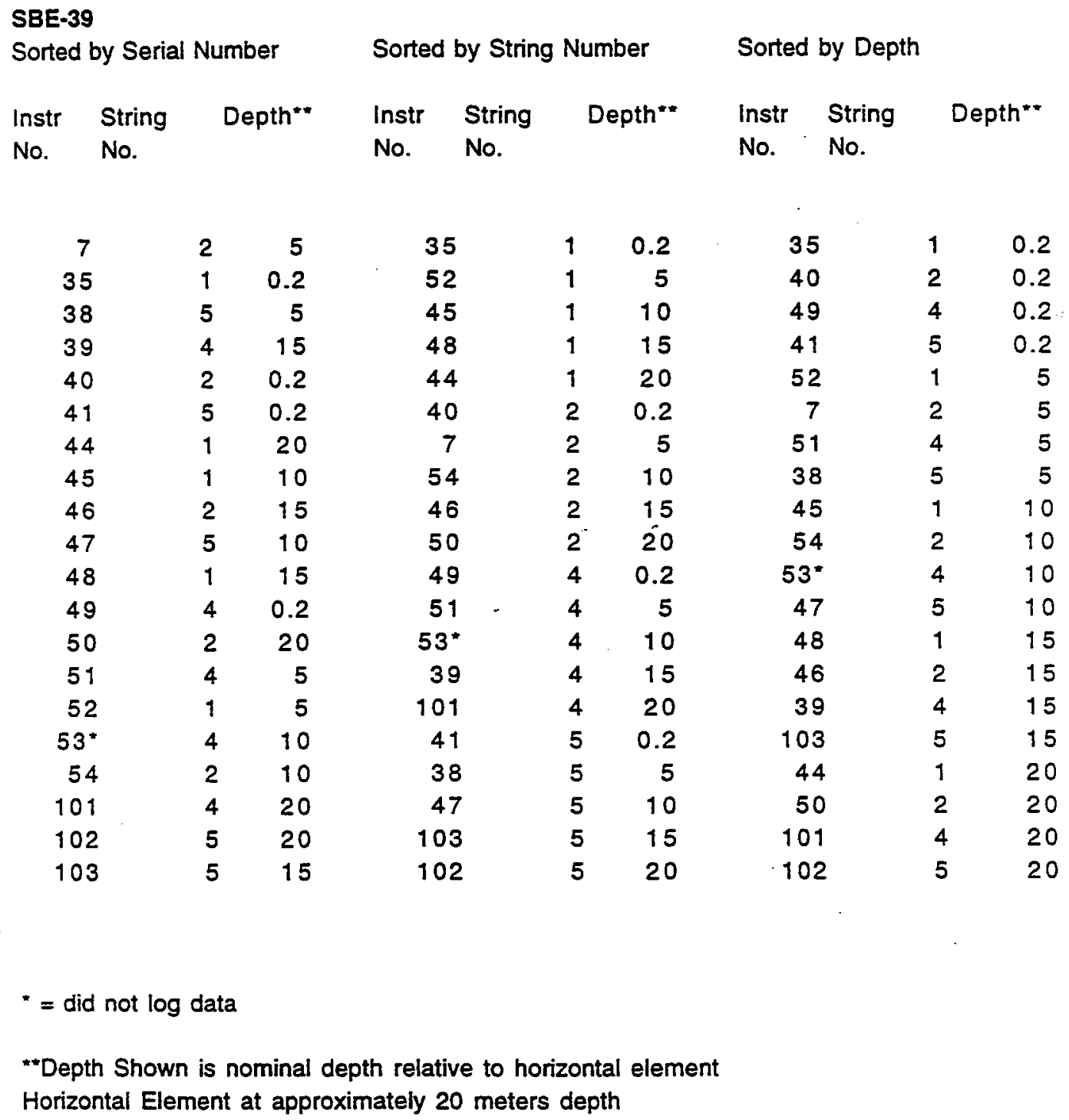


Table A1-1: Instrument type and serial number (continued)

\section{Horizontal Mooring, August 1998 Instrumentation (continued)}

\begin{tabular}{|c|c|c|c|c|c|c|c|c|}
\hline \multicolumn{3}{|c|}{ Sorted by Serial Number } & \multicolumn{3}{|c|}{ Sorted by String Number } & \multicolumn{3}{|c|}{ Sorted by Depth } \\
\hline $\begin{array}{l}\text { Instr } \\
\text { No. }\end{array}$ & $\begin{array}{l}\text { String } \\
\text { No. }\end{array}$ & Depth** & $\begin{array}{l}\text { Instr } \\
\text { No. }\end{array}$ & $\begin{array}{l}\text { String } \\
\text { No. }\end{array}$ & Depth"* & $\begin{array}{l}\text { instr. } \\
\text { No. }\end{array}$ & $\begin{array}{l}\text { String } \\
\text { No. }\end{array}$ & Depth"* \\
\hline 669 & 3 & 20 & $669 t$ & 3 & 20 & 683 & 3 & 5 \\
\hline $670 t$ & Sphere 8 & 0 & 683 & 3 & 5 & 686 & 3 & -10 \\
\hline $671 t^{*}$ & Sphere 17 & 0 & 684 & 3 & 25 & 685 & 3 & 15 \\
\hline 683 & 3 & 5 & 685 & 3 & 15 & 669 & 3 & 20 \\
\hline $684 t$ & 3 & 25 & 686 & 3 & 10 & 684 & 3 & 25 \\
\hline 685 & 3 & 15 & $671 t^{*}$ & Sphere 17 & 0 & $671 t^{*}$ & Sphere 17 & 0 \\
\hline 686 & 3 & 10 & $670 \dagger$ & Sphere 8 & 0 & 670 & Sphere 8 & 0 \\
\hline
\end{tabular}

Brancker Temperature Loggers

XL 200

Instr String Depth**

No. No.

$\begin{array}{lll}8093 & 1 & 25 \\ 8094 & 2 & 25 \\ 8091 & 4 & 25 \\ 8090 & 5 & 25\end{array}$

$\dagger=$ With pressure

- = did not collect data

"Depth Shown is nominal depth relative to horizontal element Horizontal Element at approximately 20 meters depth 
Table Al-1: Instrument type and serial number (continued)

\section{Horizontal Mooring, August 1998 Instrumentation (continued)}

FSI 3D ACM

\begin{tabular}{|c|c|c|}
\hline $\begin{array}{l}\text { Instr } \\
\text { No. }\end{array}$ & Location & $\begin{array}{c}\text { Depth** } \\
(\mathrm{m})\end{array}$ \\
\hline $1467 \dagger$ & Horiz & 20 \\
\hline 1468 & String 3 & 20 \\
\hline $1469 \dagger$ & Horiz & 20 \\
\hline
\end{tabular}

Motion Package

Instr Location Depth**

No. $\quad(m)$

001 Sphere 820

Ax Pack

Instr Location Depth**

No. (m)

$1 \quad$ String $3 \quad 25$

2 Horiz 0

$\dagger=$ With pressure

* = did not collect data

"*Depth Shown is nominal depth relative to horizontal element Horizontal Element at approximately 20 meters depth 


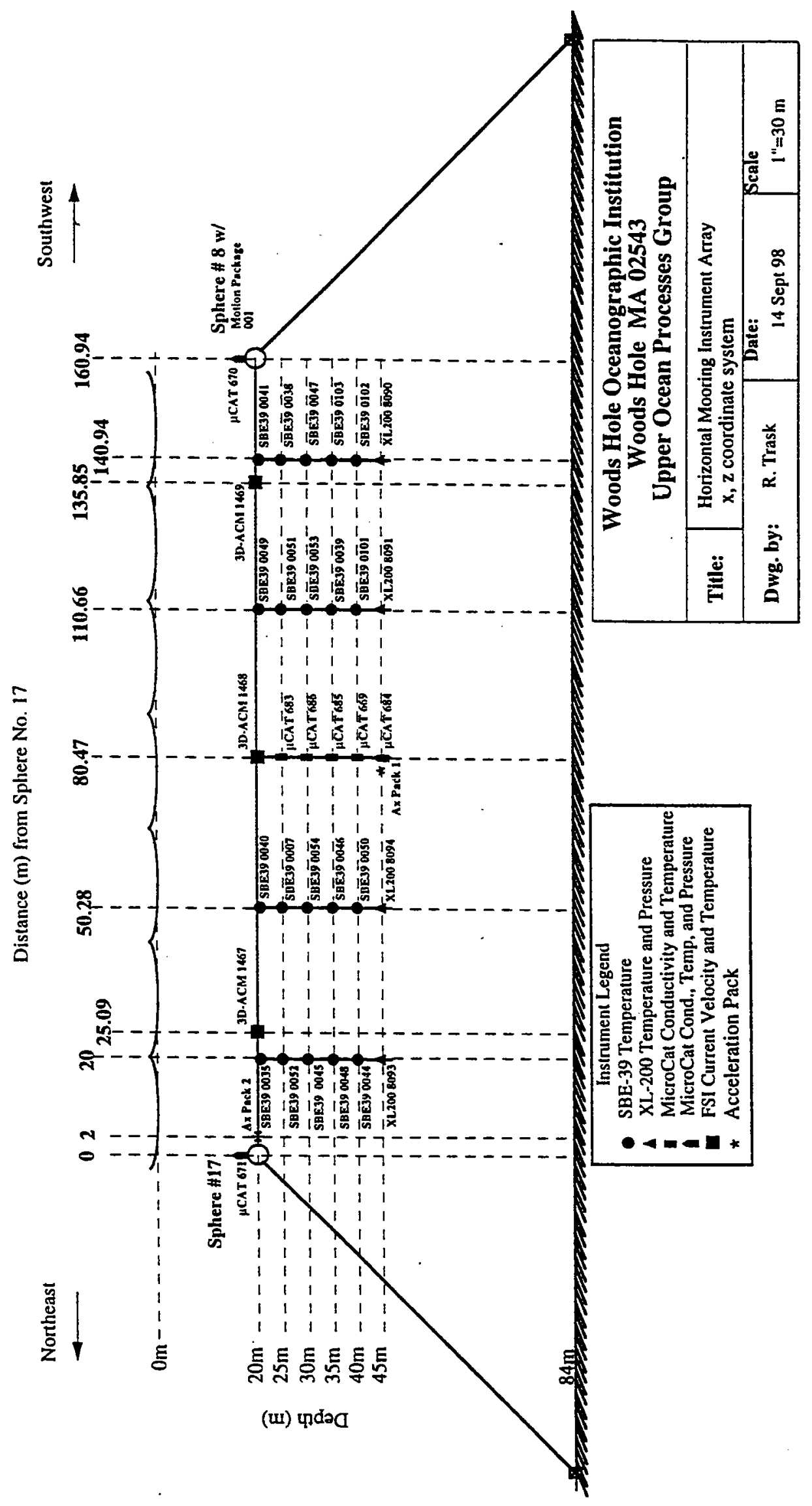

Figure A1-2: $x, z$, coordinate system. 
Table A1-2: Coordinates of deployed instrumentation using $x, z$ coordinate system

\section{Horizontal Mooring, August 1998}

Instrumentation

SBE 39

Sorted by Serial No.

Instr $\quad X \quad Z$

No. Coord Coord

$\begin{array}{ccc}7 & 50.28 & 25 \\ 35 & 20 & 20.2\end{array}$

$\begin{array}{lll}35 & 20 & 20.2\end{array}$

$\begin{array}{lll}38 & 140.9 & 25\end{array}$

$39 \quad 110.7 \quad 35$

$\begin{array}{lll}40 & 50.28 & 20.2\end{array}$

$\begin{array}{lll}41 & 140.9 & 20.2\end{array}$

$44 \quad 20 \quad 40$

$45 \quad 20 \quad 30$

$\begin{array}{lll}46 & 50.28 & 35\end{array}$

$47 \quad 140.9 \quad 30$

$48 \quad 20 \quad 35$

$\begin{array}{lll}49 & 110.7 & 20.2\end{array}$

$\begin{array}{lll}50 & 50.28 \quad 40\end{array}$

$\begin{array}{lll}51 & 110.7 & 25\end{array}$

$\begin{array}{lll}52 & 20 & 25\end{array}$

$53^{*} \quad 110.730$

$\begin{array}{lll}54 & 50.28 & 30\end{array}$

$\begin{array}{lll}101 & 110.7 & 40\end{array}$

$\begin{array}{lll}102 & 140.9 & 40\end{array}$

$\begin{array}{lll}103 & 140.9 & 35\end{array}$
Sorted by $X$ position

Instr $X \quad Z$

No. Coord Coord

$\begin{array}{lll}35 & 20 & 20.2\end{array}$

$\begin{array}{lll}52 & 20 \quad 25\end{array}$

$45 \quad 20 \quad 30$

$48 \quad 20 \quad 35$

$44 \quad 20 \quad 40$

40. $\quad 50.28 \quad 20.2$

$\begin{array}{lll}7 & 50.28 & 25\end{array}$

$\begin{array}{lll}54 & 50.28 & 30\end{array}$

$\begin{array}{lll}46 & 50.28 & .35\end{array}$

$\begin{array}{lll}50 & 50.28 & 40\end{array}$

$\begin{array}{lll}49 & 110.7 & 20.2\end{array}$

$\begin{array}{lll}51 & 110.7 & 25\end{array}$

$53^{*} 110.730$

$\begin{array}{lll}39 & 110.7 & 35\end{array}$

$\begin{array}{lll}101 & 110.7 & 40\end{array}$

$\begin{array}{lll}41 & 140.9 & 20.2\end{array}$

$\begin{array}{lll}38 & 140.9 & 25\end{array}$

$\begin{array}{lll}47 & 140.9 & 30\end{array}$

$\begin{array}{lll}103 & 140.9 \quad 35\end{array}$

$\begin{array}{lll}102 & 140.9 \quad 40\end{array}$
Sorted by $Z$ position

Instr $\mathrm{X} \quad \mathrm{Z}$

No. Coord Coord

$\begin{array}{lll}35 & 20 & 20.2\end{array}$

$\begin{array}{lll}40 & 50.28 & 20.2\end{array}$

$\begin{array}{lll}49 & 110.7 & 20.2\end{array}$

$\begin{array}{llll}41 & 140.9 & 20.2\end{array}$

$52 \quad 20 \quad 25$

$\begin{array}{lll}7 & 50.28 & 25\end{array}$

$\begin{array}{lll}51 & 110.7 & 25\end{array}$

$\begin{array}{lll}38 & 140.9 & 25\end{array}$

$45 \quad 20 \quad 30$

$\begin{array}{lll}54 & 50.28 & 30\end{array}$

$53 * 110.7 \quad 30$

$\begin{array}{lll}47 & 140.9 & 30\end{array}$

$\begin{array}{lll}48 & 20 & 35\end{array}$

$\begin{array}{lll}46 & 50.28 & 35\end{array}$

$\begin{array}{lll}39 & 110.7 & 35\end{array}$

$\begin{array}{lll}103 & 140.9 & 35\end{array}$

$44 \quad 20 \quad 40$

$\begin{array}{lll}50 & 50.28 & 40\end{array}$

$\begin{array}{lll}101 & 110.7 & 40\end{array}$

$\begin{array}{lll}102 & 140.9 \quad 40\end{array}$

$X$ and $Z$ coordinates are nominal locations

* $=$ did not log data 
Table Al-2: Coordinates of deployed instrumentation using $x, z$ coordinate system (continued)

\section{Horizontal Mooring, August 1998 Instrumentation (continued)}

MicroCat SBE-37
Sorted by Serial Number
$\begin{array}{ccc} \\ \text { Instr } & X & Z \\ \text { No. } & \text { Coord } & \text { Coord } \\ & (\mathrm{m}) & (\mathrm{m}) \\ 669 & 80.47 & 40 \\ 670 \dagger & 160.9 & 19.4 \\ 671 \dagger^{*} & 0 & 19.4 \\ 683 & 80.47 & 25 \\ 684 \dagger & 80.47 & 45 \\ 685 & 80.47 & 35 \\ 686 & 80.47 & 30\end{array}$

Sorted by $\mathrm{X}$ Position

$\begin{array}{ccc}\begin{array}{c}\text { Instr } \\ \text { No. }\end{array} & \begin{array}{c}X \\ \text { Coord } \\ (\mathrm{m})\end{array} & \begin{array}{c}Z \\ \text { Coord } \\ (\mathrm{m})\end{array} \\ 671 \dagger^{*} & 0 & 19.4 \\ 683 & 80.47 & 25 \\ 686 & 80.47 & 30 \\ 685 & 80.47 & 35 \\ 669 & 80.47 & 40 \\ 684 \dagger & 80.47 & 45 \\ 670 \dagger & 160.9 & 19.4\end{array}$

Sorted by $Z$ Position

$\begin{array}{ccc}\begin{array}{c}\text { Instr } \\ \text { No. }\end{array} & \begin{array}{c}X \\ \text { Coord } \\ (\mathrm{m})\end{array} & \begin{array}{c}Z \\ \text { Coord } \\ (\mathrm{m})\end{array} \\ 671 \dagger^{*} & 0 & 19.4 \\ 670 \dagger & 160.9 & 19.4 \\ 683 & 80.47 & 25 \\ 686 & 80.47 & 30 \\ 685 & 80.47 & 35 \\ 669 & 80.47 & .40 \\ 684 \dagger & 80.47 & 45\end{array}$

\begin{tabular}{|c|c|c|c|c|c|}
\hline \multicolumn{6}{|c|}{$\begin{array}{l}\text { Brancker Temperature Loggers } \\
X L 200\end{array}$} \\
\hline Instr & $x$ & z & Instr & $x$ & $z$ \\
\hline No. & $\begin{array}{c}\text { Coord } \\
\left(\mathrm{m}^{\prime}\right)\end{array}$ & $\begin{array}{c}\text { Coord } \\
(\mathrm{m})\end{array}$ & No. & $\begin{array}{l}\text { Coord } \\
(m)\end{array}$ & $\begin{array}{c}\text { Coord } \\
\text { (m) }\end{array}$ \\
\hline 8090 & 140.9 & 45 & 8093 & 20 & 45 \\
\hline 8091 & 110.7 & 45 & 8094 & 50.28 & 45 \\
\hline 8093 & 20 & 45 & 8091 & 110.7 & 45 \\
\hline 8094 & 50.28 & 45 & 8090 & 140.9 & 45 \\
\hline
\end{tabular}




\section{Appendix 2: Time Marks on Temperature Sensing Instruments}

Horizontal Mooring

Pre-deployment cold bath times.

Date: 4 August 98

Instrument

Time In

(UTC)

Time Out

(UTC)

Seacats

$143 \mathrm{~A}$

994

2238:31

2240:19

928

2239:17

$2241: 30$

2239:31 2241:14

993

2242:10

2244:10

991

2242:15

2244:10

929

2242:10

2244:10

Brancker's

(XX105)

4483

2245

4494

2245

3699

2245

4491

2245

4487 (spare)

2250:15

3662

2250:15

2248:18

2248:18

2248:18

2248:18

2255:13

2255:13

XI200

8092 (spare) 2250:15

8089 (spare) 2250:15

2255:13

2255:13.

Wadar

$274 \quad$ (spare) 2250:15

2250:15

2255:13

062

2255:13

SBE 39

101

2257:18

2257:08

2258:05

102

2257:08

2258:05

2258:05

String 1

2300:20

2301:19

String 2

2302:20

2303:23

2307:07

2308:09

String 4 (repeat)

2315:37

String 5

2320:50

2316:37

2321:50

MicroCats

671

2257:08

2258:05

670

2307:07

2308:09

2325:10

2326:10

String 3

2309:24

2313:30

461(USGS)

2309:25

2313:30 
Horizontal Mooring

Post-deployment cold bath times

Date: 3 September 98

Instrument

Seacats

143A

928

993

991

929

Branckers

4483

4494

3699

4491

3662

MicroCat

671

670

String 3

683

686

685

669

684

Seagauge

046

Wadar

062

String 1

String 2

String 4

String 5
Time In

(UTC)

1702:30

1644:15

1645:15

1702:30

1646:15

1559:20

1559:15

1559:15

1602:15

1559:20

1542:30

1542:50

1543:20

1543:35

1543:25

1543:15

1542:40

$1643: 15$

1706:30

1533:15

1532:15

1531:15

1538:15
Time Out

(UTC)

1718:30

1701:15

1701:15

1718:45

1701:20

1604:30

1604:30

1604:30

1606:30

1604:30

1548:20

1546:35

1546:45

1546:20

1546:15

1546:25

1548:15

1701:35

1719:30

1535:15

1536:15

$1537: 15$

1540:15

String $4 \quad$ String 5

$049 \quad 041$

$051 \quad 038$

$053 \quad 047$

$039 \quad 103$

$101 \quad 102$

$8091 \quad 8090$ 


\section{Appendix 3: Pressure Telemetry System}

A system was developed to transmit real-time pressure data to the deployment vessel using a Sea-Bird Electronics, Inc., MicroCAT (SBE 37IM) conductivity, temperature, and pressure data logger. A Sea-Bird Electronics Inductive Modem Controller (IMC) was required for communications with the MicroCAT. The IMC is supplied with DC power in the range of 7 to 25 volts and an operating current of about 60 milliamps when the modem is active. The main computer or buoy controller can be interfaced via an RS232 serial port to the IMC; the standard interface protocol between the computer / controller and the IMC is 9600 baud, 8 bits, no parity, RS-232C; with echoing of characters. The IMC (a modem is a modulator / demodulator") impresses ("modulates") the mooring cable with a Differential-Phase-Shift-Keyed (DPSK) signal that is encoded with the commands received from the computer/controller. These encoded signals are "demodulated" by the MicroCATs coupled to the mooring cable. Replies from MicroCATs are similarly coupled to the mooring cable and "demodulated" by the IMC. The DPSK communication link between the IMC and MicroCAT is half duplex, meaning that talking and listening is sequential only. Even though the data link between the IMC and the computer/controller is established at 9600 baud, the DSPK modem communication between the IMC and MicroCAT operate at 1200 baud.

The MicroCAT was set to sample every 15 seconds, with this data being stored internally. Sampling of the MicroCAT telemetry data was controlled separately by an Onset Computer Corporation, Tattletale IV data controller/logger. The Tattletale IV, which was programmed in TT Basic would send a command to request a data sample from the MicroCAT, through the IMC (Table A3-1), every 15 seconds. This data would then be sent to a FreeWave Technologies, Inc., wireless data transceiver for transmission in real time to a shipboard mounted transceiver. The IMC, Tattletale IV, and wireless transceiver were mounted on a small surface float that was tethered to the sphere-mounted MicroCAT with a 30 meter long shot of 3/16" diameter plastic jacketed wire rope. The surface float system was powered by three internal batteries, which operated at +10.5 volts $\mathrm{DC}$. The shipboard transceiver was powered by $\mathrm{AC}$.

The FreeWave transceiver required an input in the range of +9.5 to +14 volts $\mathrm{DC}$ with an average current consumption of 180 milliamps. FreeWave allows the user to tune several parameters to optimize its performance for a particular application. All adjustments are done through the FreeWave setup program, a user interface which eliminates the need for setup diskettes, DIP switches settings, or custom software. The setup program is invoked by connecting the FreeWave to any terminal program, setting the baud rate for that terminal to 19200 baud, and using a small pointed object to press the Setup buttom on the front panel of the transceiver. This procedure allowed setup of the shipboard transceiver. The transceiver used in the surface float system (OEM module) model DGRO-115, is invoked by grounding pin 2 on the main connector of that board. The output rate of the transmitted pressure data was set to 9600 baud. The transceivers were setup to run in Point to Multipoint Master mode, which allows one master (shipboard system) to simultaneously be in communication with numerous slaves (surface float systems). Both of the horizontal mooring subsurface spheres had a MicroCAT and associated pressure telemetry system. 
Table A3-1: Program used to query MicroCAT.

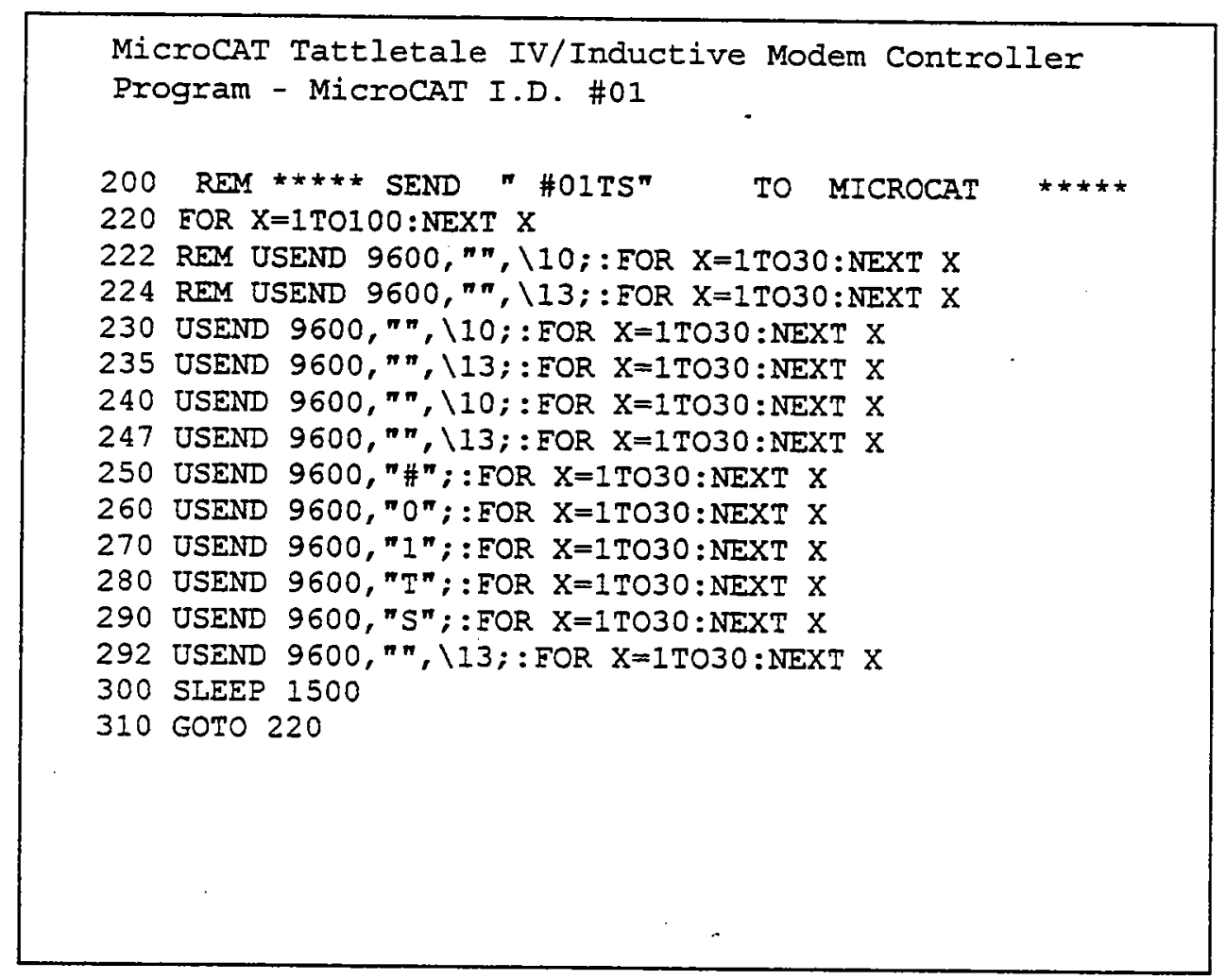

The 3/16-inch diameter wire rope that connected the sphere-mounted MicroCAT to the telemetry surface float, which housed the IMC package, was used to transmit data and receive commands. The pressure data received from the MicroCATs in real time was monitored as the ship tensioned the mooring. Tensioning was halted when the sphere reached the design depths. The TT Basic programs used in the Tattletale IV controller, interconnection drawing (Figure A3-1) and mooring schematic (Figure A3-2) are provided. 


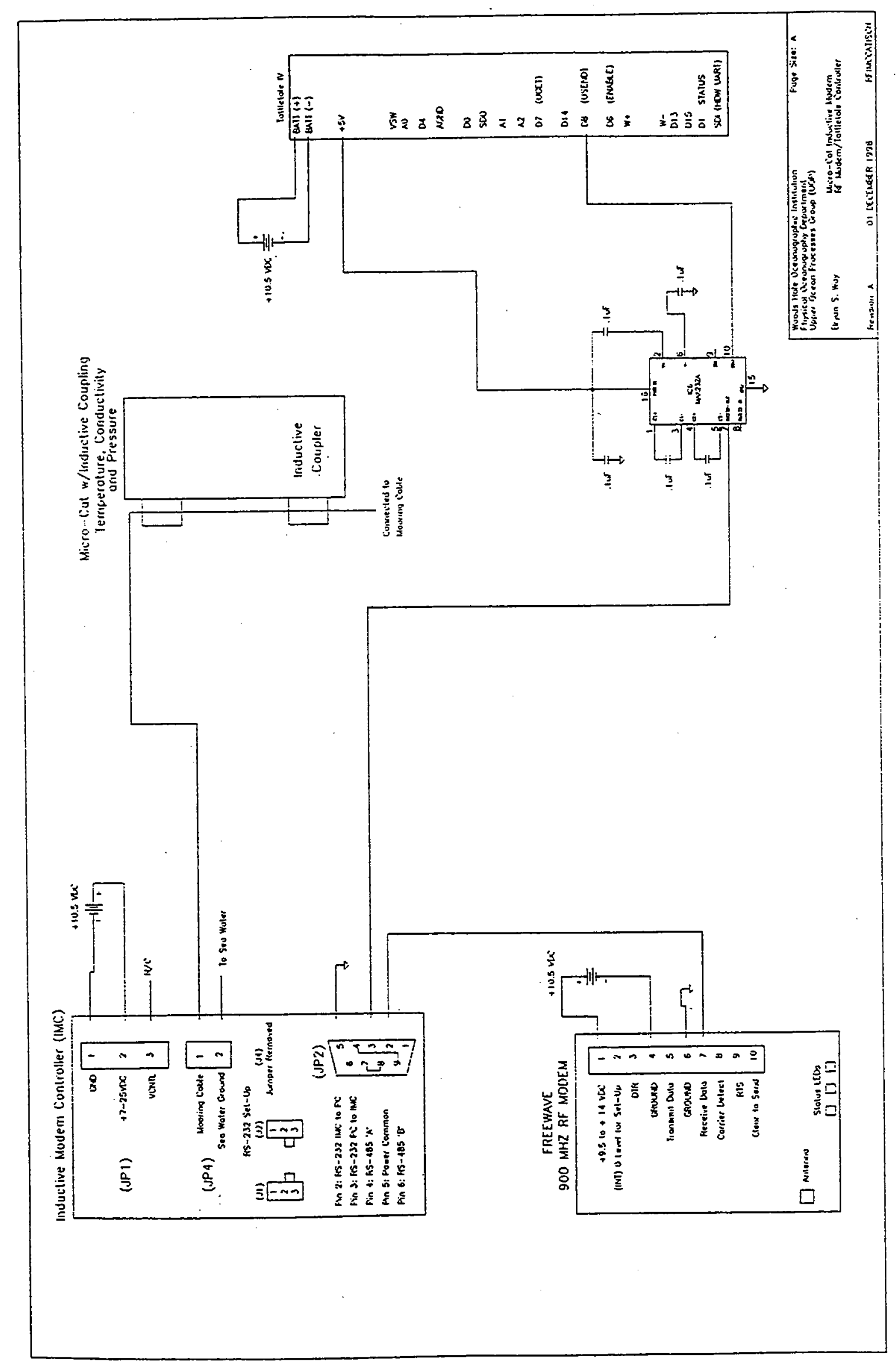

Figure A3-1: Tattle IV drawing. 


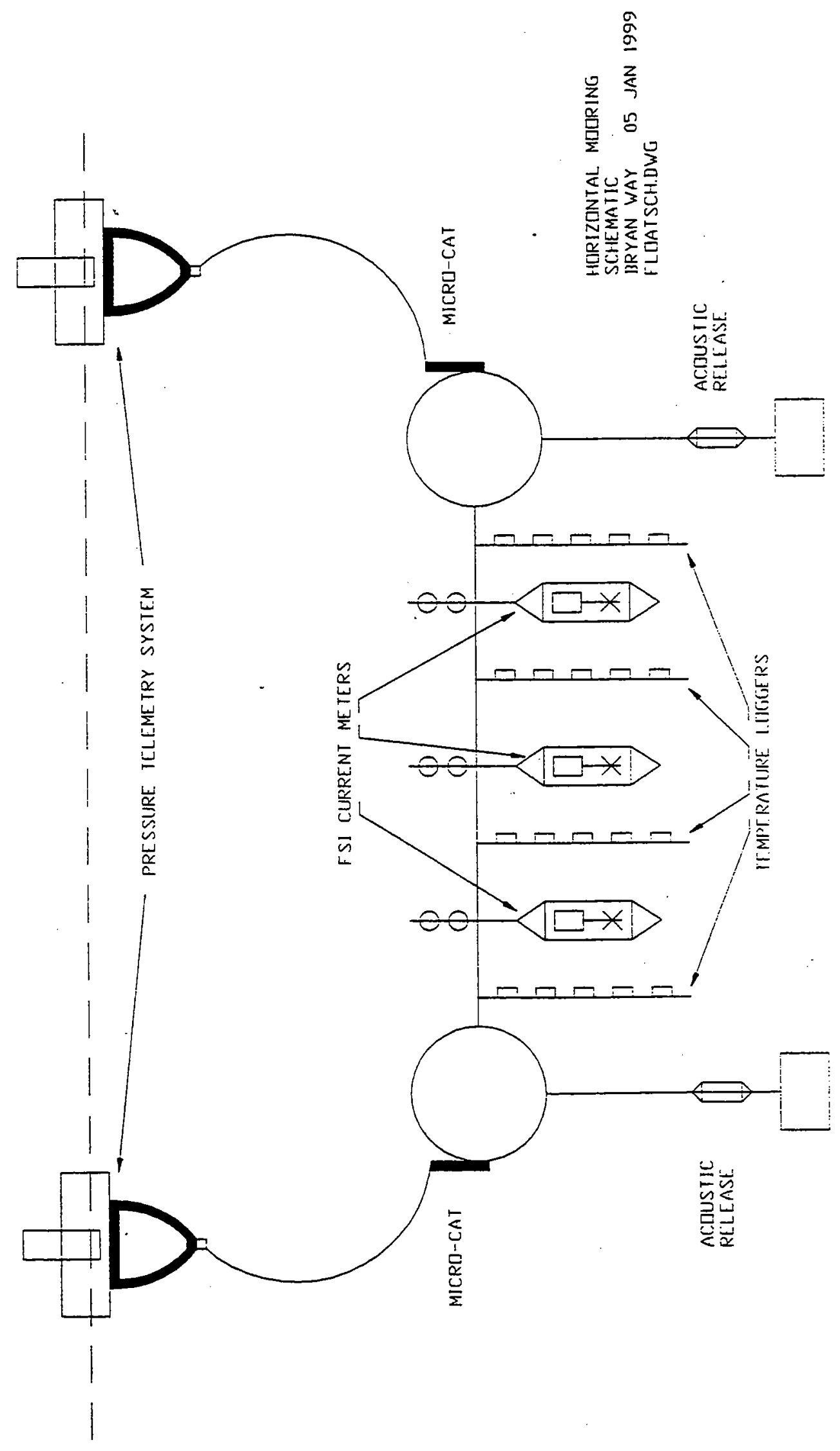

Figure A3-2: Mooring schematic. 
DOCUMENT LIBRARY

Distribution List for Technical Report Exchange - July 1998

University of California, San Diego

SIO Library $0175 \mathrm{C}$

9500 Gilman Drive

La Jolla, CA 92093-0175

Hancock Library of Biology \& Oceanography

Alan Hancock Laboratory

University of Southern California

University Park

Los Angeles, CA 90089-0371

Gifts \& Exchanges

Library

Bedford Institute of Oceanography

P.O. Box 1006

Dartmouth, NS, B2Y 4A2, CANADA

NOAA/EDIS Miami Library Center

4301 Rickenbacker Causeway

Miami, FL 33149

Research Library

U.S. Army Corps of Engineers

Waterways Experiment Station

3909 Halls Ferry Road

Vicksburg, MS 39180-6199

Marine Resources Information Center

Building E38-320

MIT

Cambridge, MA 02139

Library

Lamont-Doherty Geological Observatory

Columbia University

Palisades, NY 10964

Library

Serials Department

Oregon State University

Corvallis, OR 97331

Pell Marine Science Library

University of Rhode Island

Narragansett Bay Campus

Narragansett, RI 02882

Working Collection

Texas A\&M University

Dept. of Oceanography

College Station, TX 77843
Fisheries-Oceanography Library

151 Oceanography Teaching Bldg.

University of Washington

Seattle, WA 98195

Library

R.S.M.A.S.

University of Miami

4600 Rickenbacker Causeway

Miami, FL 33149

Maury Oceanographic Library

Naval Oceanographic Office

Building 1003 South

1002 Balch Blvd.

Stennis Space Center, MS, 39522-5001

Library

Institute of Ocean Sciences

P.O. Box 6000

Sidney, B.C. V8L 4B2

CANADA

National Oceanographic Library

Southampton Oceanography Centre

European Way

Southampton SO14 3ZH

UK

The Librarian

CSIRO Marine Laboratories

G.P.O. Box 1538

Hobart, Tasmania

AUSTRALIA 7001

Library

Proudman Oceanographic Laboratory

Bidston Observatory

Birkenhead

Merseyside L43 7 RA

UNITED KINGDOM

IFREMER

Centre de Brest

Service Documentation - Publications

BP 7029280 PLOUZANE

FRANCE 



\begin{tabular}{|c|c|c|}
\hline $\begin{array}{l}\text { REPORT DOCUMENTATION } \\
\text { PAGE }\end{array}$ & 1. REPORT NO. WHOI-99-14 & 3. Recipient's Accession No. \\
\hline \multirow{2}{*}{\multicolumn{2}{|c|}{$\begin{array}{l}\text { 4. Title and Subtitle } \\
\text { The Horizontal Mooring: A Two-Dimensional Array, Description of the Array, } \\
\text { Components, Instrumentation, Deployment and Recovery Operations }\end{array}$}} & $\begin{array}{l}\text { 5. Report Date } \\
\text { September } 1999\end{array}$ \\
\hline & & 6. \\
\hline \multicolumn{2}{|c|}{$\begin{array}{ll}\text { 7. Author(s) } & \text { Richard P. Trask, Steven P. Anderson, Bryan S. Way, William M. Ostrom } \\
& \text { Walter Paul, Mark A. Grosenbaugh, Jason I. Gobat, Robert A. Weller } \\
\end{array}$} & $\begin{array}{l}\text { 8. Performing Organization Rept. No. } \\
\text { WHOI-99-14 }\end{array}$ \\
\hline \multirow{2}{*}{\multicolumn{2}{|c|}{$\begin{array}{l}\text { 9. Performing Organization Name and Address } \\
\text { Woods Hole Oceanographic Institution } \\
\text { Woods Hole, Massachusetts } 02543\end{array}$}} & 10. Project/TaskWork Unit No. \\
\hline & & $\begin{array}{l}\text { 11. Contract(C) or Grant(G) No. } \\
\text { (C) N00014-97-1-0158 } \\
\text { (G) }\end{array}$ \\
\hline \multirow{2}{*}{\multicolumn{2}{|c|}{$\begin{array}{l}\text { 12. Sponsoring Organization Name and Address } \\
\text { Office of Naval Research }\end{array}$}} & $\begin{array}{l}\text { 13. Type of Report \& Period Covered } \\
\text { Technical Report }\end{array}$ \\
\hline & & 14 \\
\hline
\end{tabular}

\section{Supplementary Notes}

This report should be cited as: Woods Hole Oceanog. Inst. Tech. Rept., WHOI-99-14.

\section{Abstract (Limit: 200 words)}

A moored two-dimensional array with instrumentation distributed both horizontally and vertically was deployed for 27 days in August 1998 at an 85-meter deep site in Massachusetts Bay near Stellwagon basin. The horizontal mooring consisted of a 160-meter long horizontal element positioned at a depth of 20 meters between two subsurface moorings. Suspended below the horizontal member were five 25-meter long vertical strings. The vertical strings had a horizontal separation of 30 meters and each had instruments at depths of 20,25, 30, 35, 40 and 45 meters. Instrumentation deployed on the two-dimensional array included acoustic current meters, temperature sensors, conductivity measuring instruments, pressure sensors and motion monitoring packages.

This report includes a detailed description of the two-dimensional array, the anchoring system and the instrumentation that were deployed. Also included is a description of the deployment and recovery techniques that were employed, as well as an assessment of the performance of the array.

\section{Document Analysis a. Descriptors}

horizontal mooring

anchor systems

two-dimensional moored array

b. Identifiers/Open-Ended Terms

\section{c. COSATI Field/Group}

18. Availability Statement

Approved for public release; distribution unlimited.

\begin{tabular}{|c|}
\hline $\begin{array}{c}\text { 19. Security Class (This Report) } \\
\text { UNCLASSIFIED }\end{array}$ \\
\hline 20. Security Class (This Page) \\
\hline
\end{tabular}
21. No. of Pages 58

22. Price 


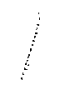


